\title{
The history of MR imaging and its reflections in Acta Radiologica
}

Hans-Jørgen Smith

Department of Radiology and Nuclear Medicine

Institute of Clinical Medicine

University of Oslo, Norway

Corresponding author:

Hans-Jørgen Smith, Idunnsvei 59, NO-1386 Asker, Norway

Email: h.j.smith@medisin.uio.no

No conflict of interest

References "Blinded for anonymity”:

22. Smith HJ. Cardiac MR imaging. Acta Radiol 1999;40:1-22.

61. Smith HJ, Bakke SJ. MR angiography of in situ and transplanted renal arteries. Acta Radiol 1993;34:150-155. 
The history of MR imaging and its reflections in Acta Radiologica 


\begin{abstract}
The first reports in Acta Radiologica on magnetic resonance imaging (MRI) were published in 1984, four years after the first commercial MR scanners became available. For the first two years, all MR papers originated from the USA. Nordic contributions started in 1986, and until 2020, authors from 44 different countries have published MR papers in Acta Radiologica. Papers on MR imaging have constituted on average $30-40 \%$ of all published original articles in Acta Radiologica, with a high of 49\% in 2019. The MR papers published since 1984 document tremendous progress in several areas such as magnet and coil design, motion compensation techniques, faster image acquisitions, new image contrast, contrast-enhanced MRI, functional MRI, and image analysis. In this historical review, all of these aspects of MRI are discussed and related to Acta Radiologica papers.
\end{abstract}

\title{
Keywords
}

Magnetic resonance imaging, history, technical aspects 
Magnetic resonance imaging (MRI) has been a part of diagnostic imaging in radiology since the early 1980 s and is thus the youngest of the main radiological modalities. Due to its nonionizing nature, unique contrast resolution, and ability to combine structural and functional information, MRI has developed into an indispensable diagnostic tool, and for many indications, it is the modality of choice. Through the pages of Acta Radiologica, the development of MRI can be followed from the early start in 1984. Prior to this start, however, many years of research formed the basis of the modality as we know it today.

\section{Short historical review}

Some discoveries or inventions are never developed into practical applications, but sometimes the conversion is very fast. When the x-rays were discovered by Wilhelm Conrad Röntgen in 1895 , it took only one year before the first institutions of medical imaging were established. When the nuclear magnetic resonance (NMR) phenomenon was discovered in 1938, it took 42 years before the discovery was developed into a new modality of diagnostic imaging. During this long period, a few milestones and main contributors should be remembered and honored.

It was the American physicist Isidor Isaac Rabi (1898-1988) who first observed the NMR phenomenon when he in 1938 sent a beam of molecules through a magnetic field and discovered that the molecules emitted radio waves at specific frequencies. For this discovery, he received the Nobel Prize in physics in 1944. In 1946 the American physicists Felix Bloch (1905-1983) and Edward Mills Purcell (1912-1997) observed the NMR phenomenon in fluids and solids, and for that achievement, they were awarded the Nobel Prize in physics in 1952. In 1951 another American physicist, Erwin Louis Hahn (1921-2016) developed a spin-echo method for studies of diffusion in fluids (but never received a Nobel Prize). The Swiss physical chemist Richard Robert Ernst (1933-2021) developed NMR spectroscopy based on 
Fourier transform in 1966 and received a Nobel Prize in chemistry in 1991. The first biomedical application of NMR took place in 1971 when the American physician Raymond Vahan Damadian (1936-) measured T1 and T2 values in rat tumors (1). Two years later, in 1973, the American chemist Paul Christian Lauterbur (1929-2007) and the English physicist Peter Mansfield (1933-2017) described how magnetic field gradients can be used to locate NMR signals, thus establishing the very basis for the generation of images (2). They both received the Nobel Prize in physiology or medicine in 2003.

The first MR scanner for imaging the human body was built by Raymond Damadian and his team in 1977. It was a superconducting magnet and was named "Indomitable". The very first scan of a human body was a single axial slice through the chest of one of the team members. The scanning was based on the field-focused nuclear MR (or FONAR) voxelimaging technique and lasted four hours and 45 minutes. The first commercial MR systems were introduced in 1980 by Oxford Instruments ( $0.15 \mathrm{~T}$ superconducting magnet) and FONAR (permanent magnet). By this time, the Fourier transform-based spin-warp imaging technique had been developed, offering a much shorter acquisition time than the field-focused NMR (3).

\section{Introduction of MRI in the Nordic countries}

Among the Nordic countries, Finland was the first to acquire MR scanners, a major reason being the fact that Finland had its own manufacturer of low-field MR magnets, Instrumentarium. The very first unit was a $0.17 \mathrm{~T}$ superconducting magnet installed at the Helsinki University Central Hospital in June 1982 (4), the result of a joint venture between the university and Instrumentarium. One year later, the system was replaced by a $0.02 \mathrm{~T}$ resistive magnet (Acutscan) from the same manufacturer. 
Sweden was next in line, having its first two magnets installed in 1984. In September 1984, a $0.5 \mathrm{~T}$ Siemens magnet was installed at Uppsala University Hospital, funded mostly by state research grants and partly by a grant from the National Society Against Cancer (5). In December the same year, a $0.02 \mathrm{~T}$ magnet (Instrumentarium) came into operation at St. Göran's Hospital in Stockholm, paid for by the hospital's own research foundation (5).

In Denmark, the first MR scanner was donated by a wealthy Danish businessman who, in 1983, had been a patient at Hvidovre Hospital in Copenhagen. Upon discharge, he expressed a desire to donate advanced diagnostic equipment that could obviate the need for uncomfortable invasive tests such as catheterization and biopsies. He was advised that an entirely new technique, MR imaging, might do the trick, and as a consequence, he donated DKK 20 million for the purchase of a $1.5 \mathrm{~T}$ magnet (Siemens), which came into operation in May 1985 (5). For four years, this was the only MR scanner in Denmark, but in 1989, five additional magnets were bought, all paid for by donations (6).

The introduction of MRI in Norway was steered by the government and the national health authorities. For several reasons, the steering was not very successful, and the intention of buying one MR unit ended up with the purchase of five units in two years from 1986 to 1987 (7). Four units were paid for by state grants and were all installed at university hospitals from October 1986 to December 1987: 0.5 T and 1.5 T (Philips) at Trondheim University Hospital, 1.5 T (Siemens) at the National Hospital (Rikshospitalet, Oslo), and 1.5 T (General Electric) at the Norwegian Radium Hospital (Oslo). The very first magnet (0.5 T Philips) was, however, installed in May 1986 at Stavanger County Hospital, a non-university hospital at that time, as a result of private initiatives and local fundraising.

The last of the Nordic countries, Iceland, had its first MR scanner (0.5 T General Electric) installed at Landspítali hospital, Reykjavík, in 1992. The installation was officially opened for 
clinical use in June (8). Landspítali was 60 years in 1990, and the MR scanner was considered an anniversary gift from the government and the nation.

\section{MRI publications in Acta Radiologica}

In this historical review, "MRI publications" in Acta Radiologica include all original articles involving the use of MRI clinically or experimentally, excluding editorials, letters, or correspondence. The first two papers on MRI in Acta Radiologica (or Acta Radiologica Diagnosis, which was the name of the journal 1963-1986) were published in the last issue (issue 6) of the 1984 volume (volume 25) $(9,10)$. In 1985, six papers involving MRI were published, constituting 5\% of the total number of papers (121) that year. From 1995 the percentage of MRI papers has been above 30 with an average of about $40 \%$, reaching a high of $49 \%$ in 2019 with 101 MRI papers of a total of 205 papers (Fig. 1).

All the first eight MRI papers (1984 and 1985) originated from the USA, but it is worth noting that six of the eight papers had a well-known Swedish radiologist as first and corresponding author: Hans Ringertz, one paper in 1984, and Holger Pettersson, five papers in 1985. In 1986, the first MRI papers from Nordic countries appeared in Acta Radiologica, two from Finland and five from Sweden. During the years 1984-2019, authors from a total of 44 countries have published MRI papers in Acta Radiologica. Ten countries have published more than 50 MRI papers during 1984-2019 (Fig. 2). The most productive country has been Sweden with 254 published MRI papers, but the majority of these papers, 154, were published in the previous millennium (1984-1999). The next two decades have shown a steady decline, with 69 Swedish MRI papers published in 2000-2009 and 31 in 2010-2019. In the last two decades, the "winners" with respect to the number of published MRI papers have been the People's Republic of China (PRC) and the Republic of Korea (South Korea) (Fig. 3). 
The published MRI papers may be categorized into 15 radiological "subspecialties" (Fig. 4), the four largest being neuroradiology (445 papers), musculoskeletal radiology (324 papers), urogenital radiology (202 papers), and abdominal and gastrointestinal radiology (179 papers).

The MRI papers published in Acta Radiologica reflect the immense technological development that has taken place for this modality in the period 1984-2019. This development may be divided into seven areas of progress: improvements in hardware, motion compensation, faster image acquisitions, new image contrast, contrast-enhanced MRI, functional MRI, and image analysis.

\section{Improvements in hardware}

\section{Magnet design}

A key factor in providing high image quality is the magnetic field of the MR magnet, its strength and homogeneity. In the early years of MRI, low field resistive magnets dominated. In 1984-1987 17 MRI papers were published in Acta Radiologica, in 14 of these a wholebody magnet was used (the remaining three being small bore magnets): resistive magnet in 10 papers ( $0.02 \mathrm{~T}$ in one and $0.15 \mathrm{~T}$ in nine papers), and superconducting magnet in four papers ( $0.35 \mathrm{~T}$ and $0.5 \mathrm{~T})$. Permanent magnets also existed in the market (e.g. the first commercial MRI system from FONAR in 1980), but results with these magnets were not published in Acta Radiologica. Eight papers involving the ultra-low field resistive system from Instrumentarium $(0.02 \mathrm{~T})$ were published in the years 1986-1994, but none later. The advantages of superconducting magnets are several: no external electric current to maintain the magnetic field (as opposed to resistive magnets), a more homogeneous magnetic field with a larger field-of-view, and higher field strength. Superconducting magnets with field strength as high as $1.5 \mathrm{~T}$ became available in 1985 , and results with such a magnet were first reported in Acta Radiologica in 1987 (11). The strive for increased spatial resolution and 
improved signal-to-noise ratio, especially in applications such as functional MRI (fMRI) of the brain (blood oxygen level-dependent [BOLD] imaging) has led to even higher field strengths in commercial systems: 3.0 T available from 1998 and first reported in Acta Radiologica in 2005 (12), and eventually 7.0 T, the first results published in Acta Radiologica in 2018 (13).

\section{Coil design}

Almost equally important for image quality as the main magnetic field is the RF (radio frequency) system or coil design. In the 1980s, transmit-receive RF coils (such as body coils and head coils) were linearly polarized, but the signal-to-noise ratio was significantly improved when these coils were replaced by quadrature or circularly polarized coils in the 1990s. Small rigid surface coils (receive only) provided a small field of view and rapid loss of signal with distance from the coil surface. Some surface coils even had to be tuned inside the magnet with long wooden sticks. A dramatic improvement in coil design took place in 1990 when the concept of phased array coils was first described and demonstrated (14). In Acta Radiologica, the advantages of phased array coils were first described in 1997, comparing body phased array with an endorectal coil in imaging of rectal tumors (15). Other major coilrelated improvements have been digital RF systems and stronger and faster gradients.

\section{Hybrid systems}

Hybrid MR systems combining MRI and positron emission tomography (PET) have become commercially available during the last decade, but PET/MRI is still not a very widespread technique. This is illustrated by the fact that only two papers on PET/MRI have been published in Acta Radiologica (before 2020), in 2012 (16) and 2017 (17), respectively. It is fascinating to combine the unique anatomic detail and functional information provided by 
MRI with PET's high sensitivity in detecting minute amounts of tracers. It may represent a diagnostic one-stop-shop and thus save time, but in most instances, the diagnostic accuracy of PET/MRI does not seem to supersede that provided by the combined use of MRI and PET separately (17).

\section{Motion compensation}

Motion in any form is the most common source of artifacts in MRI, and apart from patient motion, the major contributors are flow (in blood and cerebrospinal fluid, CSF), respiration, and cardiac contractions. Several compensatory measures to these artifacts were introduced during the 1980s and are still in use. Examples are electrocardiographic (ECG) gating (18), respiratory gating (19), spatial presaturation (20), and gradient moment nulling (21).

\section{Motion compensation in cardiac MRI}

One of the most challenging applications in MRI with respect to artifacts is cardiac imaging, the major sources of artifacts being cardiac contractions and respiratory motion. In the 1980s, imaging of cardiac anatomy with ECG gated spin-echo or cardiac function with ECG gated gradient echo (cine MRI) had acquisition times of several minutes, excluding the possibility of breath-hold. The respiratory motion could be compensated for by gating, i.e. by recording motion of the chest wall and perform imaging only in the interval of the respiratory cycle with the least motion (end-expiration) (22), but this was impractical and very time-consuming. An alternative technique known as respiratory ordered phase encoding (ROPE) had been known since 1985 (23), but was not generally available; there is only one paper in Acta Radiologica referring to this technique as part of their methods (24). The movements of the diaphragm can also be tracked with a so-called navigator echo. This technique can be combined with MR angiography (MRA) of the coronary arteries, as published in Acta Radiologica in 2003 (25). 
A breakthrough in cardiac MRI came in 1991 with the introduction of segmented data acquisition (26). The term segmented in this context means that several lines (e.g. 7-9) in kspace are filled during each cardiac cycle. The scan time is reduced accordingly, thus enabling image acquisition within a breath-hold and eliminating respiratory artifacts. Breath-hold cine MRI with segmented data acquisition has later become the "working horse" of cardiac MRI.

Even faster techniques providing real-time cine MRI of the heart without ECG gating have become available, as documented in Acta Radiologica in 2017 (27). The development of faster image acquisition is further discussed in the next section.

\section{Faster image acquisitions}

The pulse sequences provided by the first commercial MR scanners were all rather time consuming: spin-echo (SE), saturation-recovery (SR), inversion-recovery (IR), and some basic gradient-echo (GRE) sequences. A T2-weighted SE scan of the liver lasted typically 1520 minutes.

\section{Echo-planar imaging}

The potentially most rapid of all pulse sequences, echo-planar imaging (EPI), was first described by Mansfield in 1977 (28). Phase encoding was accomplished by a fluctuating phase gradient during free induction decay (T2* decay) after the excitation pulse, enabling scan times as short as 10-100 ms. The technique did not, however, become available on commercial scanners until the early 1990s. Experience with the use of EPI was first reported in Acta Radiologica in 1995 (29). Major reasons for the slow implementation of this technique were high sensitivity to magnetic field inhomogeneities, large chemical shift artifacts, and limited spatial resolution. Many modifications of EPI have been developed. 
Today, the technique is mostly used for functional applications such as BOLD imaging, diffusion, and perfusion.

\section{Short TR and low flip angle GRE imaging}

An important step forward for rapid imaging came in 1986 with the introduction of a spoiled GRE pulse sequence with a very short repetition time (TR) and low flip angle, named fast low-angle shot (FLASH) by Siemens (30). Speed was provided by dramatically reducing the TR, and adequate signal strength was achieved with a small flip angle, making breath-hold imaging possible, both in 2D and 3D. The concept of spoiled GRE with short TR and low flip angle was of course also adopted by other vendors, and the pulse sequence was consequently given other names, e.g. SPGR (spoiled gradient echo) by General Electric and T1-FFE (fast field echo) by Philips. Experience with GRE FLASH was reported in Acta Radiologica as early as 1987 (31). Although not as fast as EPI, FLASH was much more robust with respect to magnetic field inhomogeneities and chemical shift artifacts. It could not provide true T2 weighting, however.

\section{Fast spin-echo imaging}

Faster T2-weighted imaging was introduced in 1986 by the name of RARE imaging (32), the acronym meaning rapid acquisition with relaxation enhancement. A report on RARE-imaging appeared in Acta Radiologica in 1999 (33). The original RARE pulse sequence was developed into fast spin-echo (FSE) or turbo spin-echo (TSE). In Acta Radiologica, the use of fast spin-echo was first reported in 1995 (34). T2-weighted TSE/FSE pulse sequences typically have a long TR and multiple spin echoes, e.g. 7, each echo giving data for a new line in k-space. A so-called echo train length of 7 will thus reduce the acquisition time with a factor of 7, the "turbo factor". Breath-hold T2-weighting can be accomplished with a single 
shot variant named HASTE, half-Fourier acquisition single-shot turbo spin-echo, first mentioned in Acta Radiologica in 1997 (35). After a single excitation pulse, 128 spin echoes are acquired, giving data to fill half of k-space for an image with 256 pixels in the phase encoding direction.

\section{Parallel imaging and alternative reconstruction techniques}

Another boost with respect to rapid imaging came with the introduction of parallel imaging, first a technique called SMASH (simultaneous acquisition of spatial harmonics) in 1997 (36), then SENSE (sensitivity encoding) in 1999 (37). A further development of SMASH named GRAPPA (generalized autocalibrating partially parallel acquisition) was presented in 2002 (38). Parallel imaging relies on multi-channel acquisition, i.e. use of phased array coils, and the acceleration factor is improved with the number of coil elements. Parallel imaging was at the center of interest and well discussed in Acta Radiologica in 2004 (39).

Image acquisition can also be made faster with an alternative filling of k-space, e.g. spiral or radial data sampling, as reported in Acta Radiologica in 2001 (40) and 2016 (41), respectively. An even more recent image reconstruction technique (from randomly undersampled data) is called compressed sensing (42). Its usefulness in breath-hold 3D MR cholangiography was discussed in a paper in Acta Radiologica in 2019 (43).

\section{New image contrast}

The earliest commercial MR scanners were equipped with a relatively narrow range of options for image contrast, mainly T1-, proton density (PD)-, and T2-weighting. Inversionrecovery (IR) was first mainly used for heavily T1-weighting in imaging of the brain. However, it was soon realized that the principle of inversion-recovery also could generate alternative image contrast, first in 1985 with STIR (short TI inversion recovery) using a short 
inversion time (TI) to suppress signal from fat (44), and then in 1992 with FLAIR (fluidattenuated inversion recovery), using a long inversion time to suppress the signal from CSF (45). STIR and FLAIR (and its variants) soon became part of routine MR imaging, first reported in Acta Radiologica in 1990 (46) and 1997 (47), respectively.

\section{Chemical shift imaging}

The main contributors to signal in MRI are hydrogen (protons) in fat and water. These two signal components have slightly different resonance frequencies, amounting to approximately $3.5 \mathrm{ppm}$, or about $220 \mathrm{~Hz}$ at $1.5 \mathrm{~T}$. When using a 180-degree refocusing pulse, fat and water signals are always in phase when the echo is sampled, but with GRE imaging the echo time (TE) determines the relative phase of fat and water, e.g. in phase or opposed phase. So-called chemical shift imaging with separate water and fat images was first reported by Dixon in 1984 (48). His original technique has later been refined and modified, and in Acta Radiologica, the first three reports on experience with variants of the Dixon method were published in 2015 and $2016(49-51)$

Alternative methods of suppressing the signal from fat are frequency-selective water excitation, opposed phase (out-of-phase) GRE imaging, and frequency-selective fat suppression. In Acta Radiologica, the first report on frequency-selective water excitation was published in 1988 (52), experience with opposed phase GRE imaging in 1992 (53), and with frequency-selective fat suppression in 1994 (54).

\section{Magnetization transfer contrast}

The term magnetization transfer (MT) contrast dates back to 1989 (55). This technique takes advantage of the fact that hydrogen (protons) in tissues can exist in three different pools, 1) the free water pool, 2) the "bound" pool, i.e. those associated with macromolecules, and 3) 
water in the hydration layer between free water and macromolecules. The image contrast in MT imaging is accomplished by saturating the macromolecular pool of protons with an offresonance RF pulse, i.e. a pulse applied at a different frequency to the Larmor frequency of the free water protons. This causes minimal saturation of the free water protons, but by means of chemical exchange and cross-relaxation, the selective saturation is transferred to the protons in the hydration layer and also to some of the protons in the free water pool (hence the term magnetization transfer). When a new RF pulse at the free water Larmor frequency is applied, the MR signal from the free water protons is reduced due to the saturation caused by the off-resonance pulse. The signal attenuation is largest for tissues with a high degree of water-macromolecule interaction. MT contrast has several applications. In Acta Radiologica the first two papers on MT contrast appeared in 1993, both musculoskeletal applications $(56,57)$, the first paper on the use of MT contrast in combination with MR angiography was published in 1996 (58), and the usefulness of MT contrast in imaging of the central nervous system (CNS) was first reported in 2007 (59).

\section{Non-contrast-enhanced MR angiography}

Blood flow can lead to motion artifacts, but it is even more important as a source of image contrast, exploited in MR angiography (MRA). There are two main principles of noncontrast-enhanced MRA, time-of-flight (TOF) and phase-contrast (PC). TOF MRA relies on the in-flow of magnetized blood, while PC MRA exploits the phase difference between moving blood and stationary tissue. Both techniques were thoroughly described in a review article in Acta Radiologica in 1992 (60). One year later, experience with 3D TOF MRA was first reported (61), and in 1996 a comparison of 3D TOF and 3D PC MRA was published (62). Although both MRA techniques have later been refined, they are still non-breath hold, and for 
body applications, they have therefore largely been replaced by breath-hold contrast-enhanced MRA (see below).

\section{Balanced GRE imaging}

Until 1999, breath-hold cine MRI of the heart was based on spoiled gradient echo sequences with short TR and low flip angle, i.e. FLASH-type sequences. This technique relied on the inflow of fully magnetized blood into the slice being imaged during image acquisition for the blood to become bright, similar to TOF MRA. Slowly moving blood, especially when inplane, would reduce the signal strength from blood, and the delineation between blood and myocardium was often suboptimal. This was revolutionized in 1999 with the introduction of steady-state free precession gradient echo pulse sequences with balanced gradients used along all three axes, "balanced" meaning that the net gradient-induced dephasing over a TR interval is zero. It was first named trueFISP (Fast Imaging with Steady-state free Precession) by Siemens (63), then FIESTA (Fast Imaging Employing Steady-state Acquisition) by General Electric, and balanced-FFE (Fast Field Echo) by Philips. The signal strength with this pulse sequence is approximately proportional to T2/T1 ("T2/T1-weighted"), giving high signal strength to blood due to its long T2 and short T1. Balanced gradient echo sequences have become the mainstay of cine MRI of the heart, providing a uniformly high signal from blood even when flow is slow, e.g. in a left ventricular aneurysm, and much better discrimination between blood and myocardium, first shown in Acta Radiologica in 2007 (64). As reported in Acta Radiologica, balanced gradient echo sequences also have several other applications, such as non-enhanced MRA (65), MR enteroclysis (66,67), imaging of the cochlear nerve (68), and imaging in utero (69).

\section{Parameter mapping}


In the first decade of MR imaging, there was considerable interest in measuring T1- and T2relaxation in various tissues and tumors (70-72), hoping to improve tissue characterization and tumor diagnosis. Unfortunately, T1 and T2 values proved rather unspecific. Later, mapping of these and other physical parameters has added new diagnostic information. These maps are gray scale or color-coded images where the shade of gray or color of each pixel is determined by the value of the parameter in the corresponding voxel. The first report on T2 mapping in Acta Radiologica was published in 2007 (73), using T2 mapping to evaluate patellar cartilage. Evaluation of cartilage is still the most important application of T2 mapping. T2* mapping has also been used to evaluate cartilage, as shown in a paper in Acta Radiologica in 2011 (74); other applications presented in Acta Radiologica are analysis of uterine zones (75), assessment of iron overload in the liver (76), and detection of prostate cancer (77). Even T1 mapping has been used to assess articular cartilage, first reported in Acta Radiologica in 2008 (78). A major application of T1 mapping is tissue characterization of myocardium (79), and in particular quantification of diffuse myocardial fibrosis by calculating myocardial extra-cellular volume (ECV) from native and post-contrast T1 maps (80).

\section{Susceptibility-weighted imaging}

Although T2*-weighted sequences such as GRE with small flip angle and long TE and singleshot EPI with long TE are sensitive to local differences in magnetic susceptibility, and thus might have been named "susceptibility-weighted", the term "susceptibility-weighted imaging" (SWI) commonly refers to a novel fully flow compensated 3D GRE sequence with long TE. SWI exploits the susceptibility differences between compounds such as deoxygenated blood, blood products, iron, and calcium and uses the phase image to detect these differences. The final image presented is a combination of the magnitude and phase data (81). SWI is used for 
imaging of the brain and was originally called BOLD venographic imaging because the veins stand out very dark due to their high content of deoxyhemoglobin, i.e. a blood-oxygen-leveldependent (BOLD) contrast. SWI is particularly useful in head trauma and suspected acute stroke, but is also very sensitive in detecting occult low-flow vascular malformations, cerebral microbleeds, and intracranial calcifications. It furthermore plays a role in the diagnosis of neurodegenerative diseases and brain tumors. There are several examples in Acta Radiologica of the usefulness of SWI, the majority related to improved detection of hemorrhage in various conditions (82-86). Other applications reported in Acta Radiologica include measurement of iron deposition in basal ganglia in Parkinson's disease (87), and even non-cerebral applications such as grading of clear cell renal cell carcinoma (88) and evaluation of deep infiltrating endometriosis (89).

Quantitative susceptibility mapping (QSM) provides quantitative values of magnetic susceptibility, allowing differentiation of paramagnetic materials such as iron and hemorrhage from diamagnetic materials such as calcification. Only two papers on QSM have been published in Acta Radiologica (before 2020), one being concerned with iron deposition in the brain (90) and one with copper accumulation in Wilson's disease (91).

\section{Contrast-enhanced MRI}

In the early years of MRI, there was a strong belief (among some) that contrast media would never be necessary for MRI. The new modality provided T1-weighting, PD-weighting, T2weighting, and even T2*-weighting, and that ought to be more than enough. This belief did not last long, however. In 1987, the first commercial intravenous contrast agent for MRI was introduced by Schering: gadopentetate dimeglumine (Gd-DTPA, Magnevist), an extracellular, paramagnetic, gadolinium-based contrast medium with a linear, ionic chelate. Soon contrastenhanced sequences became part of routine imaging. The first applications were to improve 
the detection of tumors or inflammation through contrast enhancement on T1-weighted images, as reported in Acta Radiologica as early as 1987 (92,93). Paramagnetic contrast media have a T1-shortening effect (below a certain concentration) and are thus positive contrast media, causing increased signal intensity. The same contrast media also have a T2*shortening effect due to their paramagnetic nature and can therefore also act as negative contrast media by causing locally increased differences in magnetic susceptibility. This is most commonly exploited in perfusion imaging (see below). After the introduction of GdDTPA in 1987, several other Gd-based contrast media have been developed, including extracellular, hepatobiliary, intravascular, gastrointestinal, and tumor-selective contrast media.

\section{Gadolinium-based contrast media and nephrotoxicity}

It was for many years believed that Gd-based MR contrast media were less nephrotoxic than iodinated contrast media. In a paper published in Acta Radiologica in 1998, it was argued that Gd-DTPA could be used as an alternative x-ray contrast medium in conventional and interventional radiology in patients with contraindications for iodinated contrast media, e.g. due to reduced renal function (94). Another paper in Acta Radiologica from 2001 concluded that Gd-DTPA seems to be safe in hemodialysis patients (95). In 2004, it was shown that gadolinium contrast media are more nephrotoxic than low osmolar iodine contrast media in iso-attenuating doses (96). The only reason for less nephrotoxic effects observed with Gdcontaining contrast media was the small volume injected.

\section{Gadolinium and nephrogenic systemic fibrosis}

In 2006, another blow to the assumed safety of gadolinium contrast media hit the news: the association between these contrast media and nephrogenic systemic fibrosis (NSF) $(97,98)$. The dilemma of contrast medium-induced nephropathy vs. nephrogenic systemic fibrosis has 
been discussed in several editorials in Acta Radiologica, first in 2007 (99), then in 2009 (100), in 2012 (101), and then again twice in $2016(102,103)$. It is generally assumed that NSF, which only occurs in patients with severely reduced renal function, is caused by the free gadolinium ion, $\mathrm{Gd}^{3+}$. Gadolinium is more loosely bound in contrast media with a linear chelate structure as opposed to macrocyclic agents where the binding of $\mathrm{Gd}^{3+}$ is stronger. The risk of NSF is, therefore, largest with the linear intravenous agents, and two of these, gadopentetate dimeglumine (Magnevist) and gadodiamide (Omniscan) have been withdrawn from the market.

\section{Retention of gadolinium in tissues}

Yet another concern with gadolinium contrast agents is the retention of gadolinium in tissues in the absence of renal failure, discussed in an editorial in 2016 (104). An early documentation of gadolinium retention in brain tumors was reported in Acta Radiologica in 2010 (105).

\section{Contrast-enhanced MR angiography}

MR contrast media are used in about one-third of all MR examinations (102), and they have played an essential part in the development of contrast-enhanced MR angiography. In Acta Radiologica, the first paper on 3D contrast-enhanced MRA was published in 2000 (106). Contrast-enhanced MRA is based on a breath-hold 3D gradient-echo sequence with timing to ensure that the contrast medium has its highest concentration in the vessels of interest at the time when the central part of k-space is filled during image acquisition. Several papers published in Acta Radiologica demonstrate that the technique has later been refined with improvements in spatial resolution and acquisition time and is widely used for all body parts, including whole-body examinations (107). 


\section{Late enhancement MRI}

One particular contrast-enhanced examination that has had a great impact on cardiac imaging is late (or delayed) enhancement MRI, a technique that can show myocardial infarct and scar tissue (108). An inversion-recovery turbo GRE sequence with an appropriate choice of inversion time nulls the signal from normal myocardium, highlighting contrast-enhanced infarct or scar tissue 15-20 minutes after intravenous gadolinium contrast injection. In Acta Radiologica, experience with this technique was first reported in 2007 (109,110).

\section{Iron- and dysprosium-based contrast media}

Although the vast majority of MR contrast agents are based on gadolinium, papers in Acta Radiologica have also addressed alternatives based on iron, dysprosium, or manganese. Especially in the 1990s, superparamagnetic iron oxide (SPIO) particles were used as an oral contrast medium to decrease the signal from the gastrointestinal tract on T2-weighted images (111). Intravenously injected SPIO particles have been used in liver imaging; the particles are ingested by the macrophages in the reticuloendothelial system, resulting in a decrease in the signal of the normal liver parenchyma, thus highlighting metastases (112). Ultrasmall superparamagnetic iron oxide (USPIO) nanoparticles may also have potential as a tumortargeting contrast medium, as shown in an experimental study on breast cancer published in 2009 (113). Dysprosium-based contrast medium (Dy-DTPA-BMA, no longer available) has been used for perfusion imaging and also as a marker of tissue viability (114).

\section{Manganese-based contrast medium}

A new manganese-based contrast medium, mangafodipir trisodium (MnDPDP, Teslascan) was thoroughly presented in Acta Radiologica in 1997 (115). The contrast medium is no 
longer available, but it was first of all intended for liver imaging. After slow intravenous injection, the contrast medium was taken up in the hepatocytes, resulting in a strong and relatively long-lasting T1-shortening and thus enhancement on T1-weighted images (116). Similar enhancement was also found for the pancreas (117). Experimentally, MnDPDP has also shown intriguing potential in imaging of myocardial infarcts, as a combined diagnostic and cardioprotective agent (118).

\section{Hyperpolarized noble gases}

Paramagnetic or superparamagnetic MR contrast media act by shortening $\mathrm{T} 1, \mathrm{~T} 2$, or $\mathrm{T} 2 *$ in surrounding water molecules, i.e. they speed up relaxation processes. One type of contrast medium can be imaged directly, however: hyperpolarized noble gases. As thoroughly described in a review article in Acta Radiologica in 2000 (119), hyperpolarized 3He can be used for both static and dynamic ventilation studies, providing much higher spatial resolution than is possible with radionuclide-based ventilation methods. However, high costs and limited availability of hyperpolarized $3 \mathrm{He}$ have restricted the use of this technique to preliminary clinical studies. The results of one of these were published in Acta Radiologica in 2009 (120).

\section{Functional MRI}

The term functional MRI is often understood as meaning fMRI or BOLD imaging of the brain, but there are also many other "functions" of the body that can be explored with MRI, e.g. blood flow velocity, perfusion, diffusion, tissue elasticity, myocardial strain, and metabolism.

\section{BOLD imaging}

The blood oxygen level-dependent (BOLD) contrast was first described in 1990 (121). The BOLD contrast is based on the relative amounts in blood of deoxyhemoglobin (which is 
paramagnetic) and oxyhemoglobin (which is not paramagnetic). An increase in deoxyhemoglobin results in reduced signal strength on $\mathrm{T} 2 *$-weighted images. One might think that areas of the brain which increase their activity and therefore extract more oxyhemoglobin from blood would be seen as areas with a decreased signal. The opposite is true, however. With increased activity of the brain cells, the blood flow to the region is usually overcompensated to such a degree that venous return from the region has reduced amounts of deoxyhemoglobin. In BOLD imaging of the brain, areas with increased activity are therefore seen with increased signal strength. The BOLD signal is also dependent on the arterial partial pressure of $\mathrm{O}_{2}$ and $\mathrm{CO}_{2}$ (122). Traditionally, BOLD imaging has been used to map brain regions that are activated by certain tasks or reacting to a stimulus at a low frequency. Such a task- or paradigm-based application of fMRI was first addressed in Acta Radiologica in 2010 (123). BOLD imaging of the brain may, however, also be performed without any required cooperation from the patient, in so-called resting-state fMRI (rs-fMRI). Resting-state fMRI records the spontaneous fluctuations of the BOLD signal, allowing exploration of the modular nature of cortical function and assessment of resting-state functional connectivity. The first paper on rs-fMRI in Acta Radiologica was published in $2011(124)$.

\section{Flow quantification}

MR methods for measuring blood flow were developed long before the establishment of MR imaging. The history and methodology of flow quantification are discussed at length in a review article in Acta Radiologica in 1992 (60). With the introduction of cine 2D phasecontrast MRI in 1986 (125), flow imaging could become part of routine MRI. In the 1990s, several papers published in Acta Radiologica reported the use of phase-contrast velocity mapping in different applications such as measurement of aqueductal CSF flow $(126,127)$, 
blood flow in the superior sagittal sinus (128), renal arteries (129), and biventricular diastolic flow (130). As documented in Acta Radiologica, velocity encoded phase contrast imaging has become an important part of cardiac MRI in congenital heart disease $(131,132)$, and the technique can also be used for estimation of vessel wall shear stress $(133,134)$.

More recently, so-called four-dimensional phase-contrast velocity mapping (4D PC-MRI) has become increasingly researched (135). This technique includes three-directional velocity encoding in a three-dimensional imaging volume over time, thereby providing detailed hemodynamic information. A phantom study on 4D PC-MRI was published in Acta Radiologica in 2013 (136).

\section{Perfusion imaging with contrast media}

Measurement of microcirculation or tissue perfusion is of particular interest in ischemic disease of the heart and the brain, and in tumor detection and characterization. When perfusion is measured with MRI, this is most commonly accomplished by imaging during the first pass of a paramagnetic contrast agent. There are two principally different methods of first-pass MR perfusion imaging, dynamic susceptibility contrast (DSC) MR perfusion, and dynamic contrast-enhanced (DCE) MR perfusion. DSC MR perfusion is the most commonly used method and is based upon signal loss on T2*-weighted sequences (e.g. EPI) during the first pass of a paramagnetic contrast agent (137). When used in perfusion imaging of the brain, the most commonly calculated parameters are relative cerebral blood volume (rCBV), relative cerebral blood flow (rCBF), and mean transit time (MTT). There are numerous papers in Acta Radiologica addressing DSC MR perfusion. Most of these are related to perfusion imaging of the brain for various indications (138-144), but there are also reports on the use of DSC MRI in the differential diagnosis of breast cancer $(145,146)$. 
DCE MR perfusion, also referred to as permeability MRI, is based on the T1-shortening effect of paramagnetic contrast media, and the most commonly calculated parameter is k-trans, the volume transfer constant, a measure of capillary permeability (147). Capillary permeability is related to tumor angiogenesis. A review article published in Acta Radiologica in 2008 discusses the potential for DCE MRI of the liver in tumor characterization and as a marker of tumor angiogenesis (148). The role of DCE MRI in the detection of prostate cancer has been much discussed. A paper published in 2004 concluded that "DCE 3D EPI did not improve tumor location compared with that of T2W TSE images" (149). The value of DCE MRI in prostate cancer was also reviewed in 2008 (150). In 2010, the European Society of Urogenital Radiology (ESUR) recommended a scoring system for multiparametric MRI, Prostate Imaging-Reporting and Data System (PI-RADS) (151), and DCE MRI became part of the recommended imaging protocol. An evaluation of the accuracy of PI-RADS was published in Acta Radiologica in 2015 (152).

The value of DCE MRI has been reported in Acta Radiologica also for applications such as ischemic heart disease (153), endometrial cancer (154), orbital lesions (155), and glioma grading (156).

\section{Non-contrast perfusion imaging: arterial spin labeling}

There is a third method for MR perfusion imaging that does not require an intravenous injection of contrast medium: arterial spin labeling (ASL). ASL is intended for measurement of cerebral blood flow (CBF or rCBF) and acts by magnetic labeling of arterial blood water protons below the imaging slab. Labeled blood that flows into the imaging volume can be visualized by subtracting non-labeled (control) images from the labeled images (157). Parameters such as rCBV or MTT cannot be calculated. There are several ASL techniques. In Acta Radiologica, the first paper on ASL was published in 2008, discussing its potential for 
glioma grading (158). A paper from 2015 found comparable results with pulsed ASL and DSC MRI (159). The technical aspects of ASL were reviewed in 2018 (160).

\section{Diffusion-weighted imaging}

Diffusion is a parameter that can provide detailed information about the microstructure of tissues. Diffusion is the random Brownian motion of water molecules. Diffusion can be free, as in a collection of fluid, but in biologic tissues, diffusion is always modulated. Diffusion of extracellular water may be hindered by spherical obstacles (cells) or by cylindrical structures (e.g. fibers, dendrites), and diffusion of intracellular water is even more restricted by the cell membranes. Diffusion in tissues is furthermore anisotropic, meaning that diffusion is easier or more restricted in certain directions. Diffusion-weighted imaging (DWI) is based on measuring diffusion in a voxel of tissue (161). Very basically, this is accomplished by applying a strong magnetic field gradient (diffusion gradient) on either side of a 180-degree pulse. The net phase effect on stationary protons is zero, but diffusing protons will be dephased after the paired gradient, thus reducing the subsequent signal. A measure of the degree of diffusion weighting is the b-value, which more specifically is a measure of the diffusion gradient amplitude, the gradient duration, and the time between the paired gradients. High intravoxel diffusion means weak signal strength, and areas with restricted diffusion as compared to the surrounding tissue will have increased signal and appear bright. In DWI, the diffusion gradient is usually applied in all three orthogonal directions $(\mathrm{x}, \mathrm{y}, \mathrm{z})$ to measure the signal strength (and degree of diffusion) in all three directions. To generate isotropic DWI maps, the geometric mean of the direction-specific images is calculated. Based on the DWI images, a quantitative measure of the degree of diffusion named apparent diffusion coefficient (ADC) is calculated and presented as a parametric map. Areas with restricted diffusion, therefore, have low signal on ADC maps, but high signal on DWI images. Typical causes of 
restricted diffusion are cell edema (as in early stroke) and increased cellularity (as in tumors). Increased diffusion is associated with loss of cell integrity, as in necrosis.

Diffusion-weighted imaging has for many years been an integral part of routine MR imaging, especially in neuro- and oncologic applications. This is heavily reflected in papers published in Acta Radiologica. Among the 1771 MR papers published in Acta Radiologica 1984-2019, 225 titles contain the word diffusion. The first paper was published in 1987, a phantom and volunteer study on brain diffusion (162). The first clinical diffusion paper came in 1994, discussing ADC-values in hydrocephalus (163). The first paper on DWI in acute cerebral ischemia appeared in 1998 (164). A review article on the potential of DWI in brain tumors was published in 2006 (165). The first article on the potential of DWI in prostate cancer detection came in 2007 (166). Together with T2-weighted imaging and DCE MR perfusion, DWI has been part of PI-RADS since 2010. Detection of malignant neoplasms or metastases in practically any part of the body benefits from DWI, as the following few examples from Acta Radiologica illustrate: pancreas $(167,168)$, liver $(169,170)$, lung $(171,172)$, breast $(173,174)$, head and neck $(175,176)$, and lymph nodes $(177)$.

\section{Intravoxel incoherent motion imaging}

It should be noted that the signal attenuation in DWI is not only caused by true diffusion, but also by blood microcirculation. Due to the multidirectional structure of capillary networks within a voxel, capillary blood flow has also an apparently random motion, also named "pseudo-diffusion". Both diffusion and perfusion are therefore part of the phenomenon termed intravoxel incoherent motion (IVIM). Fortunately for DWI, the blood microcirculation component decays 10 times faster than diffusion, meaning that perfusion has little impact on ADC-values at high b-values. It also means that diffusion and perfusion can be separated at low b-values. The concept of IVIM dates back to 1986 (178). Thanks to technological 
developments (especially EPI) so-called IVIM imaging has gained renewed interest as a method for non-contrast perfusion (179). IVIM imaging was first presented in Acta Radiologica in 1997, discussing its use in ischemic stroke (180). In more recent years, its main application has been oncology, and similar to other MR perfusion techniques it has been used to assess tumor characteristics such as neoangiogenesis and microvascular heterogeneity. Among the malignancies studied and reported in Acta Radiologica are hepatic lesions (181), endometrial cancer (182), renal cancer (183), lung cancer (184), rectal cancer (185), and glioma (186).

\section{Diffusion tensor imaging}

The fact that diffusion is anisotropic is exploited in diffusion tensor imaging (DTI). By applying diffusion gradients in many directions, it is possible to visualize fiber directions, e.g. the white matter tracts in the CNS. So-called fiber tractography has more recently been applied also outside the CNS. In Acta Radiologica, the majority of papers addressing DTI have focused on CNS. The first paper appeared in 2004 on the "usefulness of diffusion tensor imaging of white matter in Alzheimer disease and vascular dementia" (187). The first nonCNS application was published in 2011, addressing DTI of the prostate (188). As documented in Acta Radiologica, DTI has also been applied to lesions in the breast (189), liver (190), and endometrium (191).

\section{Diffusion kurtosis imaging}

A further extension of DTI is diffusion kurtosis imaging (DKI), which estimates the kurtosis, or skewed (non-Gaussian) distribution of water diffusion (192). It can be used to characterize neural tissue, e.g. in the diagnosis of stroke (193), but in Acta Radiologica, the majority of papers on diffusion kurtosis imaging or non-Gaussian diffusion have focused on non-CNS 
applications such as prostate cancer (194), pulmonary nodules (195), hepatic fibrosis (196), and hepatic tumor (197).

\section{MR elastography}

Elasticity is another property of tissues that may be measured and visualized with MRI, using MR elastography, a technique that was introduced in 1995 (198). Shear waves generated by special hardware and propagating into the body are detected by MR imaging using a modified phase-encoding gradient. MR elastography appears to be promising in the assessment of liver fibrosis (199), and in 2014, a review article on liver fibrosis was published in Acta

Radiologica, discussing the latest developments in imaging, including MR elastography (200). As reported in Acta Radiologica, MR elastography has also been used in other organs systems to study brain tumors (201), prostate cancer (202), and chronic renal allograft dysfunction (203).

\section{Myocardial strain imaging}

Myocardial stiffness or lack of elasticity may be one of several causes of myocardial contractile dysfunction, but this myocardial abnormality is not studied with MR elastography. The MR method of choice is called myocardial strain imaging. Originally, the method employed tagging of the myocardium at end-diastole with presaturation strips or grids (204). Tagging was performed on cine images, and by following the deformation of the demagnetized grid pattern, detailed information on regional strain and strain rate could be obtained using dedicated software. In Acta Radiologica, this tagging technique was presented in a paper published in 1993 (205). More recently, special software has been developed, allowing tissue tracking and strain analysis with ordinary cine acquisitions, i.e. without any tagging. Results with this technique were published in Acta Radiologica in 2019 (206). 


\section{Metabolic imaging: MR spectroscopy}

The last functional tissue parameter to be discussed is metabolism. MR spectroscopy (MRS) is the procedure of choice for the non-invasive assessment of metabolites. The method was invented decades prior to the introduction of MR imaging and was used extensively in basic science before it became part of clinical MRI. Clinical MRS requires field strength of at least 1.5 T, and although MRS was available on the first $1.5 \mathrm{~T}$ scanners in the mid-1980s, it was a rather cumbersome technique, very far from being user friendly. Nevertheless, the first papers on MRS in Acta Radiologica were published as early as 1988 (207) and 1990 (208), on 31P and $1 \mathrm{H}$ spectroscopy of the human brain, respectively. Since then, a variety of techniques have become available for clinical use, including single-voxel and 3D spectroscopy, all characterized by a high degree of user-friendliness. MRS is now routinely used to characterize tumors in the brain and other organs and to evaluate inborn metabolic disorders. Papers published in Acta Radiologica have presented results with the use of MRS in characterizing tumors in the brain (209-211), breast (212), and prostate (213). MRS has also been used to study the energetic status in the heart (214).

\section{Image analysis: histogram and texture}

A well-known marker of malignancy is intratumor heterogeneity. Radiologic interpretation of tumors includes assessment of size, shape, signal intensity, contrast enhancement, and parameter metrics from diffusion and perfusion, but none of these features are very good at estimating tumor heterogeneity. Image analyses such as histogram and texture analysis can provide added value to MRI through quantitative assessments of tumor heterogeneity (215). Histogram analysis explores the frequency distribution of pixel intensities in the region of interest and uses first-order statistics to report quantitative factors such as mean, standard 
deviation, mode, maximum and minimum, kurtosis, skewness, percentiles, and entropy.

Texture analysis employs many different models for the assessment of tissue heterogeneity, including statistical-based modeling using first-, second-, and higher-order statistics (216). In Acta Radiologica, it was reported in 2014 that histogram analysis of ADC maps could help in differentiating mass-forming focal pancreatitis from pancreatic cancer (217) and also in predicting the histological grade of endometrial cancer (218). Likewise, histogram analysis of ADC maps was shown to help predict complete response in locally advanced rectal cancer post-chemoradiotherapy (219), in predicting recurrence of cervical carcinoma treated with definitive chemoradiotherapy (220), and also in predicting early response in cervical carcinoma during treatment with chemoradiotherapy (221). A paper published in 2018 showed that histogram analysis of DCE-MRI-derived parameters (K-trans and Kep) could facilitate the differentiation of oligodendroglioma from astrocytoma (222). In 2019, it was reported that texture analysis of computed tomography (CT) and MRI combined could be valuable in predicting overall survival in patients with oropharyngeal squamous cell carcinoma (223).

Texture analysis is an integral part of the emerging field of radiology known as radiomics: the conversion of digital medical images into mineable high-dimensional data. The so-called hidden image data being used in radiomics are known as features. Features can be semantic (shape, size, vascularity, spiculation, necrosis, etc.) or agnostic (histogram, texture, wavelets, etc.). The various features are extracted from segmented volumes, e.g. a tumor or part of a tumor, and placed in large databases together with other data, e.g. clinical, genomic. These data are then mined to develop diagnostic, predictive, or prognostic models for outcomes of interest (224). A further discussion of radiomics as part of artificial intelligence (AI) is beyond the scope of this historical review, but there is no doubt that AI will have a great impact on radiology in the future. 


\section{Conclusion}

Papers on MRI published in Acta Radiologica since 1984 document a tremendous technological development paired with impressive advances in diagnostic performance. The primary beneficiaries of these advances are the patients: MRI has, to a considerable degree, obviated the need for uncomfortable and potentially harmful procedures, and the high diagnostic precision of MRI has contributed to better patient care. Modern treatment is dependent upon detailed diagnostic information, and in many instances, this information can only be provided by MRI. 


\section{References}

1. Damadian RV. Tumor detection by nuclear magnetic resonance. Science $1971 ; 171: 1151-1153$

2. Lauterbur PC. Image formation by induced local interactions: examples of employing nuclear magnetic resonance. Nature 1973;242:190-191.

3. Edelstein WA, Hutchison JM, Johnson G, et al. Spin warp NMR imaging and applications to human whole-body imaging. Phys Med Biol 1980;25:751-756.

4. Spri. Magnetisk resonanstomografi i Norden (Magnetic resonance imaging in the Nordic countries). Spri rapport 223:1. Stockholm: Spri, 1987.

5. Spri. Magnetisk resonanstomografi i Norden (Magnetic resonance imaging in the Nordic countries). Spri rapport 223:2. Stockholm: Spri, 1987.

6. Spri. Magnetisk resonanstomografi: användning och omfattning i Norden (Magnetic resonance imaging: diffusion and utilization in Scandinavia). Spri rapport 279. Stockholm: Spri, 1990.

7. Bratt C. Lokale initiativ og sentral plan. Hvordan innføringen av magnettomografer i norsk sykehusvesen brøt med statens planer (Local initiatives and central plans. How the introduction of MRI in the Norwegian health care system violated state plans). Helsetjenesteforskning rapport nr. 6/1990. Oslo: Statens institutt for folkehelse, 1990.

8. Morgunblaðið June 12, 1992:24.

9. Ringertz HG, Brasch RC, Brody A, et al. Magnetic resonance imaging of vascular lesions in children: assessment of flow patterns. Acta Radiol Diagnosis 1984;25:449456.

10. Kaude JV, Kekomäki M, Walker D, et al. Imaging of unilateral hydronephrosis in an experimental animal model: with special reference to magnetic resonance. Acta Radiol Diagnosis 1984;25:501-506. 
11. Holtås SL, Plewes DB, Simon JH, et al. Technical aspects on magnetic resonance imaging of the spine at 1.5 tesla. Acta Radiol 1987;28:375-381.

12. Ludescher B, Martirosian P, Lenk S, et al. High-resolution magnetic resonance imaging of trabecular bone in the wrist at 3 tesla: initial results. Acta Radiol 2005;46:306-309.

13. Laader A, Beiderwellen $\mathrm{K}$, Kraff O, et al. Non-enhanced versus low-dose contrastenhanced renal magnetic resonance angiography at $7 \mathrm{~T}$ : a feasibility study. Acta Radiol 2018;59:296-304.

14. Roemer PB, Edelstein WA, Hayes CE, et al. The NMR phased array. Magn Reson Med 1990;16:192-225.

15. Blomqvist L, Holm T, Rubio C, et al. Rectal tumours - MR imaging with endorectal and/or phased-array coils, and histopathological staging on giant sections. Acta Radiol 1997;38:437-444.

16. Stegger L, Martirosian P, Schwenzer N, et al. Simultaneous PET/MR imaging of the brain: feasibility of cerebral blood flow measurements with FAIR-TrueFISP arterial spin labeling MRI. Acta Radiol 2012;53:1066-1072.

17. Deuschl C, Nensa F, Grueneisen J, et al. Diagnostic impact of integrated 18F-FDG PET/MRI in cerebral staging of patients with non-small cell lung cancer. Acta Radiol 2017;58:991-996.

18. Hawkes RC, Holland GN, Moore WS, et al. Nuclear magnetic resonance (NMR) tomography of the normal heart. J Comput Assist Tomogr 1981;5:605-612.

19. Wood ML, Runge VM, Henkelmra NM. Overcoming motion in abdominal MR imaging. AJR Am J Roentgenol 1988;150:513-522. 
20. Felmlee EP, Ehman RL. Spatial presaturation. A method for suppressing flow artifacts and improving depiction of vascular anatomy in MR imaging. Radiology 1987;164:559-564.

21. Mitchell DG, Vinitiski S, Burk DL Jr, et al. Motion artifact reduction in MR imaging of the abdomen. Gradient moment nulling versus respiratory-sorted phase encoding. Radiology 1988;169:155-160.

22. Blinded for anonymity.

23. Bailes DR, Gilderdale DJ, Bydder GM, et al. Respiratory ordered phase encoding (ROPE): a method for reducing respiratory motion artefacts in MR imaging. J Comput Assist Tomogr 1985;9:835-838.

24. Papanikolaou N, Karantanas A, Lavdas E. MR imaging of the liver using an ultrafast 3D multi-shot EPI sequence. Acta Radiol 1999;40:322-325.

25. Ikonen AEJ, Manninen HI, Vainio P, et al. Three-dimensional respiratory-gated coronary MR angiography with reference to X-ray coronary angiography. Acta Radiol 2003;44:583-589.

26. Atkinson DJ, Edelman RR. Cineangiography of the heart in a single breath hold with a segmented turboFLASH sequence. Radiology 1991;178:357-360.

27. Goebel J, Nensa F, Schemuth HP, et al. Real-time SPARSE-SENSE cine MR imaging in atrial fibrillation: a feasibility study. Acta Radiol 2017;58:922-928.

28. Mansfield P. Multi-planar image formation using NMR spin echoes. J Phys C Solid State Phys 1977;10:L55-L58.

29. Aronen HJ, Glass J, Pardo FS, et al. Echo-planar MR cerebral blood volume mapping of gliomas. Acta Radiol 1995;36:520-528.

30. Haase A, Frahm J, Matthaei D, et al. FLASH Imaging: rapid NMR imaging using low flip angle pulses. J Magn Reson 1986;67:258-266. 
31. Schroth G, Grodd W, Guhl L, et al. Magnetic resonance imaging in small lesions of the central nervous system. Acta Radiol 1987;28:667-672.

32. Hennig J, Nauerth A, Friedburg H. RARE imaging: a fast imaging method for clinical MR. Magn Reson Med 1986;3:823-833.

33. Kern S, Zimmerhackl LB, Hildebrandt F, et al. RARE-MR-urography - a new diagnostic method in autosomal recessive polycystic kidney disease. Acta Radiol 1999;40:543-544.

34. Blomqvist L, von Rosen A, Hindmarsh T. MR imaging of adult colo-rectal intussusception. Acta Radiol 1995;36:656-658.

35. Muhle C, Brinkmann G, Brossmann J, et al. Kinematic MR imaging of the ankle initial results with ultra-fast sequence imaging. Acta Radiol 1997;38:885-889.

36. Sodickson DK, Manning WJ. Simultaneous acquisition of spatial harmonics (SMASH): fast imaging with radiofrequency coil arrays. Magn Reson Med 1997;38:591-603.

37. Pruessmann PK, Weiger M, Scheidegger MB, et al. SENSE: sensitivity encoding for fast MRI. Magn Reson Med 1999;42:952-962.

38. Griswold MA, Jakob PM, Heidemann RM, et al. Generalized autocalibrating partially parallel acquisitions (GRAPPA). Magn Reson Med 2002;47:1202-1210.

39. Gaa J, Weidauer S, Requardt M, et al. Comparison of intracranial 3D-ToF-MRA with and without parallel acquisition techniques at $1.5 \mathrm{~T}$ and $3.0 \mathrm{~T}$ : preliminary results. Acta Radiol 2004;45:327-332.

40. Chen ZG, Li TQ, Hindmarsh T. Diffusion tensor trace mapping in normal adult brain using single-shot EPI technique: a methodological study of the aging brain. Acta Radiol 2001;42:447-458. 
41. AlObaidy M, Ramalho M, Busireddy KKR, et al. Surrogate arterial phase imaging using a long duration $(\approx 1.5 \mathrm{~min})$ radial acquisition T1-weighted sequence: an alternative in patients unable to breath-hold. Acta Radiol 2016;57:955-963.

42. Lustig M, Donoho D, Pauly JM. Sparse MRI: the application of compressed sensing for rapid MR imaging. Magn Reson Med 2007;58:1182-1195.

43. Ono A, Arizono S, Kohno S, et al. Diagnostic accuracy of 3D breath-hold MR cholangiography using compressed sensing acceleration in visualizing non-dilated biliary system in living donor liver transplantation donors. Acta Radiol 2019;60:12091215.

44. Bydder GM, Young IR. MR imaging: clinical use of the inversion recovery sequence. J Comput Assist Tomogr 1985;9:659-675.

45. De Coene B, Hajnal JV, Gatehouse P, et al. MR of the brain using fluid-attenuated inversion recovery (FLAIR) pulse sequences. AJNR Am J Neuroradiol 1992;13:15551564.

46. Lien HH, Blomlie V, Heimdal K. Magnetic resonance imaging of malignant extradural tumors with acute spinal cord compression. Acta Radiol 1990;31:187-190.

47. Reuter M, Tetzlaff K, Hutzelmann A, et al. MR imaging of the central nervous system in diving-related decompression illness. Acta Radiol 1997;38:940-944.

48. Dixon WT. Simple proton spectroscopic imaging. Radiology 1984;153:189-194.

49. Yoon JH, Lee JM, Yu MH, et al. Fat-suppressed, three-dimensional T1-weighted imaging using high-acceleration parallel acquisition and a dual-echo Dixon technique for gadoxetic acid-enhanced liver MRI at 3 T. Acta Radiol 2015;56:1454-1462.

50. Tomura N, Saginoya T, Kokubun M, et al T. T2-weighted IDEAL fast spin echo imaging of the brachial plexus: comparison with STIR. Acta Radiol 2015;56:12421247. 
51. Dong H, Li Y, Yu K, Li H. Comparison of image quality and application values on different field-of-view diffusion-weighted imaging of breast cancer. Acta Radiol 2016;57:19-24.

52. Larsson HBW, Thomsen C, Frederiksen J, et al. Chemical shift selective magnetic resonance imaging of the optic nerve in patients with acute optic neuritis. Acta Radiol 1988;29:629-632.

53. Tsushima $\mathrm{Y}$, Ishizaka $\mathrm{H}$, Kato $\mathrm{T}$, et al. Differential diagnosis of adrenal masses using out-of-phase Flash imaging. Acta Radiol 1992;33:262-265.

54. Simon JH, Rubinstein D, Brown M, et al. Quantitative contrast-enhanced MR imaging of the optic nerve. Acta Radiol 1994;35:526-531.

55. Wolff SD, Balaban RS. Magnetization transfer contrast (MTC) and tissue water proton relaxation in vivo. Magn Reson Med 1989;10:135-144.

56. Koskinen SK, Komu MES. Low-field strength magnetization transfer contrast imaging of the patellar cartilage. Acta Radiol 1993;34:124-126.

57. Mattila KT, Komu MES, Koskinen SK, et al. Exercise-induced changes in magnetization transfer contrast of muscles. Acta Radiol 1993;34:559-562.

58. Cronqvist M, Ståhlberg F, Larsson EM, et al. Evaluation of time-of-flight and phasecontrast MRA sequences at $1.0 \mathrm{~T}$ for diagnosis of carotid artery disease. Acta Radiol $1996 ; 37: 267-277$.

59. Vasudev MK, Jayakumar PN, Srikanth SG, et al. Quantitative magnetic resonance techniques in the evaluation of intracranial tuberculomas. Acta Radiol 2007;48:200206.

60. Ståhlberg F, Ericsson A, Nordell B, et al. MR imaging, flow and motion. Acta Radiol 1992;33:179-200.

61. Blinded for anonymity. 
62. Cronqvist M, Ståhlberg F, Larsson EM, et al. Evaluation of time-of-flight and phasecontrast MRA sequences at $1.0 \mathrm{~T}$ for diagnosis of carotid artery disease. Acta Radiol $1996 ; 37: 267-277$.

63. Bundy J, Simonetti O, Laub G, et al. Segmented trueFISP cine imaging of the heart [abstr]. In: Proceedings of the Seventh Meeting of the International Society for Magnetic Resonance in Medicine; 1999 May 24-28; Berkeley, CA. Berkeley, CA: International Society for Magnetic Resonance in Medicine, 1999:1282.

64. Barbier EC, Johansson L, Lind L, et al. The exactness of left ventricular segmentation in cine magnetic resonance imaging and its impact on systolic function values. Acta Radiol 2007;48:285-291.

65. Angeretti MG, Lumia D, Canì A, et al. Non-enhanced MR angiography of renal arteries: comparison with contrast-enhanced MR angiography. Acta Radiol $2013 ; 54: 749-756$

66. Asbach P, Breitwieser C, Diederichs G, et al. Cine magnetic resonance imaging of the small bowel: comparison of different oral contrast media. Acta Radiol 2006;47:899906.

67. Negaard A, Sandvik L, Mulahasanovic A, et al. Magnetic resonance enteroclysis in the diagnosis of small-intestinal Crohn's disease: diagnostic accuracy and inter- and intraobserver agreement. Acta Radiol 2006;47:1008-1016.

68. Yan F, Li J, Xian J, et al. The cochlear nerve canal and internal auditory canal in children with normal cochlea but cochlear nerve deficiency. Acta Radiol 2013;54:292298.

69. Kim JA, Narra VR. Magnetic resonance imaging with true fast imaging with steadystate precession and half-Fourier acquisition single-shot turbo spin-echo sequences in cases of suspected placenta accreta. Acta Radiol 2004;45:692-698. 
70. Pettersson H, Fitzsimmons J, Krop D, et al. Magnetic resonance imaging of the extremities: II. T1 and T2 relaxation times of muscle and fat normal values, reproducibility and dependence on physiologic variations. Acta Radiol Diagnosis $1985 ; 26: 413-416$

71. Larsson E-M, Englund E, Györffy-Wagner Z, et al. Regional differences in the proton magnetic resonance relaxation times $\mathrm{T} 1$ and $\mathrm{T} 2$ within the normal human brain. Acta Radiol Diagnosis 1986;27:231-234.

72. Englund E, Brun A, Larsson E-M, et al. Tumours of the central nervous system: proton magnetic resonance relaxation times $\mathrm{T} 1$ and $\mathrm{T} 2$ and histopathologic correlates. Acta Radiol Diagnosis 1986;27:653-659.

73. Hannila I, Nieminen MT, Rauvala E, et al. Patellar cartilage lesions: comparison of magnetic resonance imaging and T2 relaxation-time mapping. Acta Radiol 2007;48:444-448.

74. Miese FR, Zilkens C, Holstein A, et al. Assessment of early cartilage degeneration after slipped capital femoral epiphysis using T2 and T2* mapping. Acta Radiol 2011;52:106-110.

75. Imaoka I, Nakatsuka T, Araki T, et al. T2* relaxometry mapping of the uterine zones. Acta Radiol 2012;53:473-477.

76. Ibrahim E-SH, Khalifa AM, Eldaly AK. MRI T2* imaging for assessment of liver iron overload: study of different data analysis approaches. Acta Radiol 2016;57:1453-1459.

77. Wu L-M, Yao Q-Y, Zhu J, et al. T2* mapping combined with conventional T2weighted image for prostate cancer detection at 3.0 T MRI: a multi-observer study. Acta Radiol 2017;58:114-120. 
78. Kwack K-S, Cho JH, Kim MS, et al. Comparison study of intraarticular and intravenous gadolinium-enhanced magnetic resonance imaging of cartilage in a canine model. Acta Radiol 2008;49:65-74.

79. Walter TC, Knobloch G, Canaan-Kuehl S, et al. Segment-by-segment assessment of left ventricular myocardial affection in Anderson-Fabry disease by non-enhanced T1mapping. Acta Radiol 2017;58:914-921.

80. Caballeros M, Bartolomé P, Fernández González Ó, et al. Effect of contrast dose in the quantification of myocardial extra-cellular volume in adenosine stress/rest perfusion cardiac magnetic resonance examinations. Acta Radiol 2017;58:809-815.

81. Haacke EM, Xu Y, Cheng Y-CN, et al. Susceptibility weighted imaging (SWI). Magn Reson Med 2004;52:612-618.

82. Zeng Q-S, Kang X-S, Li C-F, et al. Detection of hemorrhagic hypointense foci in radiation injury region using susceptibility-weighted imaging. Acta Radiol 2011;52:115-119.

83. Yamashita E, Kanasaki Y, Fujii S, et al. Comparison of increased venous contrast in ischemic stroke using phase-sensitive MR imaging with perfusion changes on flowsensitive alternating inversion recovery at 3 tesla. Acta Radiol 2011;52:905-910.

84. Hayashida Y, Kakeda S, Hiai Y, et al. Diagnosis of intracranial hemorrhagic lesions: comparison between 3D-SWAN (3D T2*-weighted imaging with multi-echo acquisition) and 2D-T2*-weighted imaging. Acta Radiol 2014;55:201-207.

85. Qin Y, Ogawa T, Fujii S, et al. High incidence of asymptomatic cerebral microbleeds in patients with hemorrhagic onset-type moyamoya disease: a phase-sensitive MRI study and meta-analysis. Acta Radiol 2015;56:329-338. 
86. Liu G, Ghimire P, Pang H, et al. Improved sensitivity of 3.0 tesla susceptibilityweighted imaging in detecting traumatic bleeds and its use in predicting outcomes in patients with mild traumatic brain injury. Acta Radiol 2015;56:1256-1263.

87. Kwon GH, Jang J, Choi HS, et al. The phase value of putamen measured by susceptibility weighted images in Parkinson's disease and in other forms of Parkinsonism: a correlation study with F18 FP-CIT PET. Acta Radiol 2016;57:852860.

88. Chen J, Sun J, Xing W, et al. Prediction of nuclear grade of clear cell renal cell carcinoma with MRI: intratumoral susceptibility signal intensity versus necrosis. Acta Radiol 2014;55:378-384.

89. Cimsit C, Yoldemir T, Guclu M, et al. Susceptibility-weighted magnetic resonance imaging for the evaluation of deep infiltrating endometriosis: preliminary results. Acta Radiol 2016;57:878-885.

90. Xia S, Zheng G, Shen W, et al. Quantitative measurements of brain iron deposition in cirrhotic patients using susceptibility mapping. Acta Radiol 2015;56:339-346.

91. Saracoglu S, Gumus K, Doganay S, et al. Brain susceptibility changes in neurologically asymptomatic pediatric patients with Wilson's disease: evaluation with quantitative susceptibility mapping. Acta Radiol 2018;59:1380-1385.

92. Paajanen H, Brasch RC, Schmiedl U, et al. Magnetic resonance imaging of local soft tissue inflammation using gadolinium-DTPA. Acta Radiol 1987;28:79-83.

93. Valk J, de Slegte RGM, Crezee FC, et al. Contrast enhanced magnetic resonance imaging of the brain using gadolinium-DTPA. Acta Radiol 1987;28:659-665.

94. Vehmas T, Markkola AT. Gd-DTPA as an alternative contrast agent in conventional and interventional radiology. Acta Radiol 1998;39:223-226. 
95. Okada S, Katagiri K, Kumazaki T, et al. Safety of gadolinium contrast agent in hemodialysis patients. Acta Radiol 2001;42:339-341.

96. Elmståhl B, Nyman U, Leander P, et al. Gadolinium contrast media are more nephrotoxic than a low osmolar iodine medium employing doses with equal x-ray attenuation in renal arteriography: an experimental study in pigs. Acad Radiol 2004;11:1219-1228.

97. Grobner T. Gadolinium: a specific trigger for the development of nephrogenic fibrosing dermopathy and nephrogenic systemic fibrosis. Nephrol Dial Transplant 2006;21:1104-1108.

98. Marckmann P, Skov L, Rossen K, et al. Nephrogenic systemic fibrosis: suspected causative role of gadodiamide used for contrast-enhanced magnetic resonance imaging. J Am Soc Nephrol 2006;17:2359-2362.

99. Thomsen HS, Marckmann P, Logager VB. Enhanced computed tomography or magnetic resonance imaging: a choice between contrast medium-induced nephropathy and nephrogenic systemic fibrosis? Acta Radiol 2007;48:593-596.

100. Lind Ramskov K, Thomsen HS. Nephrogenic systemic fibrosis and contrast mediuminduced nephropathy: a choice between the devil and the deep blue sea for patients with reduced renal function? Acta Radiol 2009;50:965-967.

101. Thomsen HS, Bennet CL. Six years after. Acta Radiol 2012;53:827-829.

102. Thomsen HS. Nephrogenic systemic fibrosis: a serious adverse reaction to gadolinium -1997-2006-2016. Part 1. Acta Radiol 2016;57:515-520.

103. Thomsen HS. Nephrogenic systemic fibrosis: a serious adverse reaction to gadolinium -1997-2006-2016. Part 2. Acta Radiol 2016;57:643-648.

104. Thomsen HS. T1 hyperintensity in the brain after multiple intravenous injections of gadolinium-based contrast agents. Acta Radiol 2016;57:389-291. 
105. Xia D, Davis RL, Crawford JA, et al. Gadolinium released from MR contrast agents is deposited in brain tumors: in situ demonstration using scanning electron microscopy with energy dispersive X-ray spectroscopy. Acta Radiol 2010;51:1126-1136.

106. Sueyoshi E, Sakamoto I, Matsuoka Y, et al. Symptomatic peripheral vascular tree stenosis: comparison of subtracted and nonsubtracted 3D contrast-enhanced MR angiography with fat suppression. Acta Radiol 2000;41:133-138.

107. Bannas P, Finck-Wedel AK, Buhk J-H, et al. Comparison of whole body MR angiography at 1.5 and 3 tesla in patients with hereditary hyperlipidemia. Acta Radiol $2011 ; 52: 547-553$.

108. Kim RJ, Fieno DS, Parrish TB, et al. Relationship of MRI delayed contrast enhancement to irreversible injury, infarct age, and contractile function. Circulation 1999;100:1992-2002.

109. Wang L, Zhu HY, Tian JM, et al. Magnetic resonance imaging in determination of myocardial ischemia and viability: comparison with positron emission tomography and single-photon emission computed tomography in a porcine model. Acta Radiol 2007;48:500-507.

110. Aras A, Anik Y, Demirci A, et al. Magnetic resonance imaging measurement of left ventricular blood flow and coronary flow reserve in patients with chronic heart failure due to coronary artery disease. Acta Radiol 2007;48:1092-1100.

111. Øksendal AN, Bach-Gansmo T, Jacobsen TF, et al. Oral magnetic particles. Acta Radiol 1993;34:187-193.

112. Müller RD, Vogel K, Neumann K, et al. Spio-MR imaging versus double-phase spiral CT in detecting malignant lesions of the liver. Acta Radiol 1999;40:628-635. 
113. Li X, Du X, Huo T, et al. Specific targeting of breast tumor by octreotide-conjugated ultrasmall superparamagnetic iron oxide particles using a clinical 3.0-tesla magnetic resonance scanner. Acta Radiol 2009;50:583-594.

114. Nilsson S, Wikström M, Martinussen HJ, et al. Dy-DTPA-BMA as an indicator of tissue viability in MR imaging. Acta Radiol 1995;36:338-345.

115. Tirkkonen B, Aukrust A, Couture E, et al. Physicochemical characterisation of mangafodipir trisodium. Acta Radiol 1997;38:780-789.

116. Ni Y, Marchal G. Clinical implications of studies with MnDPDP in animal models of hepatic abnormalities. Acta Radiol 1997;38:724-731.

117. Ahlström H, Gehl HB. Overview of MnDPDP as a pancreas-specific contrast agent for MR imaging. Acta Radiol 1997;38:660-664.

118. Karlsson JOG, Brurok H, Eriksen M, et al. Cardioprotective effects of the MR contrast agent MnDPDP and its metabolite MnPLED upon reperfusion of the ischemic porcine myocardium. Acta Radiol 2001;42:540-547.

119. Guenther D, Hanisch G, Kauczor H. Functional MR imaging of pulmonary ventilation using hyperpolarized noble gases. Acta Radiol 2000;41:519-528.

120. Stavngaard T, Søgaard LV, Batz M, et al. Progression of emphysema evaluated by MRI using hyperpolarized 3He (HP 3He) measurements in patients with alpha-1antitrypsin (A1AT) deficiency compared with CT and lung function tests. Acta Radiol 2009;50:1019-1026.

121. Ogawa S, Lee TM, Kay AR, et al. Brain magnetic resonance imaging with contrast dependent on blood oxygenation. Proc Natl Acad Sci U S A 1990;87:9868-9872.

122. Nasrallah FA, Yeow LY, Biswal B, et al. Dependence of BOLD signal fluctuation on arterial blood $\mathrm{CO} 2$ and $\mathrm{O} 2$ : implication for resting-state functional connectivity. Neuroimage 2015;117:29-39. 
123. Engström M, Karlsson M, Croné M, et al. Clinical fMRI of language function in aphasic patients: reading paradigm successful, while word generation paradigm fails. Acta Radiol 2010;51:679-686.

124. Silfverhuth MJ, Remes J, Starck T, et al. Directional connectivity of resting state human fMRI data using cascaded ICA-PDC analysis. Acta Radiol 2011;52:1037-1042.

125. Nayler L, Firmin DN, Longmore DB. Blood flow imaging by cine magnetic resonance. J Comput Assist Tomogr 1986;10:715-722.

126. Mascalchi M, Arnetoli G, Inzitari D, et al. Cine-MR imaging of aqueductal CSF flow in normal pressure hydrocephalus syndrome before and after CSF shunt. Acta Radiol $1993 ; 34: 586-592$.

127. Barkhof F, Kouwenhoven M, Scheltens P, et al. Phase-contrast cine MR imaging of normal aqueductal CSF flow. Acta Radiol 1994;35:123-130.

128. Gideon P, Thomsen C, Gjerris F, et al. Measurement of blood flow in the superior sagittal sinus in healthy volunteers, and in patients with normal pressure hydrocephalus and idiopathic intracranial hypertension with phase-contrast cine MR imaging. Acta Radiol 1996;37:171-176.

129. Cortsen M, Petersen LJ, Ståhlberg F, et al. MR velocity mapping measurement of renal artery blood flow in patients with impaired kidney function. Acta Radiol $1996 ; 37: 79-84$

130. Kroft LJM, de Roos A. Biventricular diastolic cardiac function assessed by MR flow imaging using a single angulation. Acta Radiol 1999;40:563-568.

131. Ntsinjana HN, Tann O, Taylor AM. Trends in pediatric cardiovascular magnetic resonance imaging. Acta Radiol 2013;54:1063-1074. 
132. Kohi MP, Ordovas KG, Naeger DM, et al. CMR assessment of right ventricular function in patients with combined pulmonary stenosis and insufficiency after correction of tetralogy of Fallot. Acta Radiol 2013;54:1132-1137.

133. Sui B, Gao P, Lin Y, et al. Assessment of wall shear stress in the common carotid artery of healthy subjects using 3.0-tesla magnetic resonance. Acta Radiol 2008;49:442-449.

134. Sui B, Gao P, Lin Y, et al. Blood flow pattern and wall shear stress in the internal carotid arteries of healthy subjects. Acta Radiol 2008;49:806-814.

135. Markl M, Frydrychowicz A, Kozerke S, et al. 4D flow MRI. J Magn Reson Imaging 2012;36:1015-1036.

136. Nilsson A, Bloch KM, Töger J, et al. Accuracy of four-dimensional phase-contrast velocity mapping for blood flow visualizations: a phantom study. Acta Radiol 2013;54:663-671.

137. Villringer A, Rosen BR, Belliveau JW, et al. Dynamic imaging with lanthanide chelates in normal brain: contrast due to magnetic susceptibility effects. Magn Reson Med 1988;6:164-174.

138. Wirestam R, Borg M, Brockstedt S, et al. Perfusion-related parameters in intravoxel incoherent motion MR imaging compared with CBV and CBF measured by dynamic susceptibility-contrast MR technique. Acta Radiol 2001;42:123-128.

139. Kim JH, Lee E-J, Lee S-J, et al. Reliability of perfusion MR imaging in symptomatic carotid occlusive disease: cerebral blood volume, mean transit time and time-to-peak. Acta Radiol 2002;43:360-364.

140. Kim JH, Lee E-J, Lee S-J, et al. Comparative evaluation of cerebral blood volume and cerebral blood flow in acute ischemic stroke by using perfusion-weighted MR imaging and SPECT. Acta Radiol 2002;43:365-370. 
141. Stenberg L, Englund E, Wirestam R, et al. Dynamic susceptibility contrast-enhanced perfusion magnetic resonance (MR) imaging combined with contrast-enhanced MR imaging in the follow-up of immunogene-treated glioblastoma multiforme. Acta Radiol 2006;47:852-861.

142. Griffiths PD, Pandya H, Wilkinson ID, et al. Sequential dynamic gadolinium magnetic resonance perfusion-weighted imaging: effects on transit time and cerebral blood volume measurements. Acta Radiol 2006;47:1079-1084.

143. Thomsen H, Steffensen E, Larsson EM. Perfusion MRI (dynamic susceptibility contrast imaging) with different measurement approaches for the evaluation of blood flow and blood volume in human gliomas. Acta Radiol 2012;53:95-101.

144. Xing W, Wang X, Xie F, et al. Application of dynamic susceptibility contrastenhanced perfusion in temporal lobe epilepsy. Acta Radiol 2013;54:107-112.

145. Kvistad KA, Lundgren S, Fjøne HE, et al. Differentiating benign and malignant breast lesions with T2*-weighted first pass perfusion imaging. Acta Radiol 1999;40:45-51.

146. Zhang B, Zhu B, Li M, et al. Comparative utility of MRI perfusion with MSIDR and DWIBS for the characterization of breast tumors. Acta Radiol 2012;53:607-614.

147. Tofts PS, Brix G, Buckley DL, et al. Estimating kinetic parameters from dynamic contrast-enhanced T(1)-weighted MRI of a diffusable tracer: standardized quantities and symbols. J Magn Reson Imaging 1999;10:223-232.

148. Wang L, Van den Bos IC, Hussain SM, et al. Post-processing of dynamic gadoliniumenhanced magnetic resonance imaging exams of the liver: explanation and potential clinical applications for color-coded qualitative and quantitative analysis. Acta Radiol 2008;49:6-18.

149. Storaas T, Gjesdal KI, Svindland A, et al. Dynamic first pass 3D EPI of the prostate: accuracy in tumor location. Acta Radiol 2004;45:584-590. 
150. Fuchsjäger M, Shukla-Dave A, Akin O, et al. Prostate cancer imaging. Acta Radiol 2008;49:107-120.

151. Dickinson L, Ahmed HU, Allen C, et al. Magnetic resonance imaging for the detection, localisation, and characterisation of prostate cancer: recommendations from a European consensus meeting. Eur Urol 2011;59:477-494.

152. Reisæter LA, Fütterer JJ, Halvorsen OJ, et al. 1.5-T multiparametric MRI using PIRADS: a region by region analysis to localize the index-tumor of prostate cancer in patients undergoing prostatectomy. Acta Radiol 2015;56:500-511.

153. Szolar DH, Saeed M, Wendland M, et al. Quantification of area at risk during coronary occlusion and reperfusion by means of MR perfusion imaging. Acta Radiol 1997;38:479-488.

154. Fasmer KE, Bjørnerud A, Ytre-Hauge S, et al. Preoperative quantitative dynamic contrast-enhanced MRI and diffusion-weighted imaging predict aggressive disease in endometrial cancer. Acta Radiol 2018;59:1010-1017.

155. Erb-Eigner K, Asbach P, Ro S-R, et al. DCE-MR imaging of orbital lesions: diagnostic performance of the tumor flow residence time $\tau$ calculated by a multicompartmental pharmacokinetic tumor model based on individual factors. Acta Radiol 2019;60:643-652.

156. Su C-Q, Lu S-S, Han Q-Y, et al. Intergrating conventional MRI, texture analysis of dynamic contrast-enhanced MRI, and susceptibility weighted imaging for glioma grading. Acta Radiol 2019;60:777-787.

157. Detre JA, Rao H, Wang DJ, et al. Applications of arterial spin labeled MRI in the brain. J Magn Reson Imaging 2012;35:1026-1037.

158. Kim MJ, Kim HS, Kim JH, et al. Diagnostic accuracy and interobserver variability of pulsed arterial spin labeling for glioma grading. Acta Radiol 2008;49:450-457. 
159. Oner AY, Eryurt B, Ucar M, et al. pASL versus DSC perfusion MRI in lateralizing temporal lobe epilepsy. Acta Radiol 2015;56:477-481.

160. Havsteen I, Damm Nybing J, Christensen H, et al. Arterial spin labeling: a technical overview. Acta Radiol 2018;59:1232-1238.

161. Koh D-M, Collins DJ. Diffusion-weighted MRI in the body: applications and challenges in oncology. AJR Am J Roentgenol 2007;188:1622-1635.

162. Thomsen $\mathrm{C}$, Henriksen $\mathrm{O}$, Ring P. In vivo measurement of water self diffusion in the human brain by magnetic resonance imaging. Acta Radiol 1987;28:353-361.

163. Gideon P, Thomsen C, Gjerris F, et al. Increased self-diffusion of brain water in hydrocephalus measured by MR imaging. Acta Radiol 1994;35:514-519.

164. Li TQ, Chen ZG, Hindmarsh T. Diffusion-weighted MR imaging of acute cerebral ischemia. Acta Radiol 1998;39:460-473.

165. Bode MK, Ruohonen J, Nieminen MT, et al. Potential of diffusion imaging in brain tumors: a review. Acta Radiol 2006;47:585-594.

166. Morgan VA, Kyriazi S, Ashley SE, et al. Evaluation of the potential of diffusionweighted imaging in prostate cancer detection. Acta Radiol 2007;48:695-703.

167. Wiggermann P, Grützmann R, Weissenböck A, et al. Apparent diffusion coefficient measurements of the pancreas, pancreas carcinoma, and mass-forming focal pancreatitis. Acta Radiol 2012;53:135-139.

168. Kang B-K, Kim JH, Byun JH, et al. Diffusion-weighted MRI: usefulness for differentiating intrapancreatic accessory spleen and small hypervascular neuroendocrine tumor of the pancreas. Acta Radiol 2014;55:1157-1165.

169. Schmid-Tannwald C, Thomas S, Ivancevic MK, et al. Diffusion-weighted MRI of metastatic liver lesions: is there a difference between hypervascular and hypovascular metastases? Acta Radiol 2014;55:515-523. 
170. Kaya B, Koc Z. Diffusion-weighted MRI and optimal b-value for characterization of liver lesions. Acta Radiol 2014;55:532-542.

171. Tanaka R, Horikoshi H, Yoshida T, et al. Diffusion-weighted magnetic resonance imaging in differentiating the invasiveness of small lung adenocarcinoma. Acta Radiol $2011 ; 52: 750-755$.

172. Deng Y, Li X, Lei Y, et al. Use of diffusion-weighted magnetic resonance imaging to distinguish between lung cancer and focal inflammatory lesions: a comparison of intravoxel incoherent motion derived parameters and apparent diffusion coefficient. Acta Radiol 2016;57:1310-1317.

173. Wu L-M, Chen J, Hu J, et al. Diffusion-weighted magnetic resonance imaging combined with T2-weighted images in the detection of small breast cancer: a singlecenter multi-observer study. Acta Radiol 2014;55:24-31.

174. Chung J, Youk JH, Kim J-A, et al. Role of diffusion-weighted MRI: predicting axillary lymph node metastases in breast cancer. Acta Radiol 2014;55:909-916.

175. Razek AAKA, Megahed AS, Denewer A, et al. Role of diffusion-weighted magnetic resonance imaging in differentiation between the viable and necrotic parts of head and neck tumors. Acta Radiol 2008;49:364-370.

176. Srinivasan A, Dvorak R, Rohrer S, et al. Initial experience of 3-tesla apparent diffusion coefficient values in characterizing squamous cell carcinomas of the head and neck. Acta Radiol 2008;49:1079-1084.

177. Song J, Hu Q, Huang J, et al. Combining tumor size and diffusion-weighted imaging to diagnose normal-sized metastatic pelvic lymph nodes in cervical cancers. Acta Radiol 2019;60:388-395. 
178. Le Bihan D, Breton E, Lallemand D, et al. MR imaging of intravoxel incoherent motions: application to diffusion and perfusion in neurologic disorders. Radiology $1986 ; 161: 401-407$.

179. Le Bihan D. What can we see with IVIM MRI? NeuroImage 2019;187:56-67.

180. Wirestam R, Brockstedt S, Lindgren A, et al. The perfusion fraction in volunteers and in patients with ischaemic stroke. Acta Radiol 1997;38:961-964.

181. Watanabe H, Kanematsu M, Goshima S, et al. Characterizing focal hepatic lesions by free-breathing intravoxel incoherent motion MRI at 3.0 T. Acta Radiol 2014;55:11661173.

182. Liu J, Wan Y, Wang Z, et al. Perfusion and diffusion characteristics of endometrial malignancy based on intravoxel incoherent motion MRI at $3.0 \mathrm{~T}$ : comparison with normal endometrium. Acta Radiol 2016;57:1140-1148.

183. Zhu Q, Ye J, Zhu W, et al. Value of intravoxel incoherent motion in assessment of pathological grade of clear cell renal cell carcinoma. Acta Radiol 2018;59:121-127.

184. Deng Y, Li X, Lei Y, et al. Use of diffusion-weighted magnetic resonance imaging to distinguish between lung cancer and focal inflammatory lesions: a comparison of intravoxel incoherent motion derived parameters and apparent diffusion coefficient. Acta Radiol 2016;57:1310-1317.

185. Yang X, Xiao X, Lu B, et al. Perfusion-sensitive parameters of intravoxel incoherent motion MRI in rectal cancer: evaluation of reproducibility and correlation with dynamic contrast-enhanced MRI. Acta Radiol 2019;60:569-577.

186. Miyoshi F, Shinohara Y, Kambe A, et al. Utility of intravoxel incoherent motion magnetic resonance imaging and arterial spin labeling for recurrent glioma after bevacizumab treatment. Acta Radiol 2018;59:1372-1379. 
187. Sugihara S, Kinoshita T, Matsusue E, et al. Usefulness of diffusion tensor imaging of white matter in Alzheimer disease and vascular dementia. Acta Radiol 2004;45:658663.

188. Li C, Chen M, Li S, et al. Diffusion tensor imaging of prostate at 3.0 tesla. Acta Radiol 2011;52:813-817.

189. Tsougos I, Svolos P, Kousi E, et al. The contribution of diffusion tensor imaging and magnetic resonance spectroscopy for the differentiation of breast lesions at $3 \mathrm{~T}$. Acta Radiol 2014;55:14-23.

190. Erturk SM, Ichikawa T, Kaya E, et al. Diffusion tensor imaging of cysts, hemangiomas, and metastases of the liver. Acta Radiol 2014;55:654-660.

191. Zhang L, Liu A, Zhang T, et al. Use of diffusion tensor imaging in assessing superficial myometrial invasion by endometrial carcinoma: a preliminary study. Acta Radiol 2015;56:1273-1280.

192. Jensen JH, Helpern JA, Ramani A, et-al. Diffusional kurtosis imaging: the quantification of non-gaussian water diffusion by means of magnetic resonance imaging. Magn Reson Med 2005;53:1432-1440.

193. Hui ES, Fieremans E, Jensen JH, et al. Stroke assessment with diffusional kurtosis imaging. Stroke 2012;43:2968-2973.

194. Li C, Chen M, Wan B, et al. A comparative study of Gaussian and non-Gaussian diffusion models for differential diagnosis of prostate cancer with in-bore transrectal MR-guided biopsy as a pathological reference. Acta Radiol 2018;59:1395-1402.

195. Das SK, Yang DJ, Wang JL, et al. Non-Gaussian diffusion imaging for malignant and benign pulmonary nodule differentiation: a preliminary study. Acta Radiol 2017;58:19-26. 
196. Yoon JH, Lee JM, Lee KB, et al. Comparison of monoexponential, intravoxel incoherent motion diffusion-weighted imaging and diffusion kurtosis imaging for assessment of hepatic fibrosis. Acta Radiol 2019;60:1593-1601.

197. Budjan J, Sauter EA, Zoellner FG, et al. Diffusion kurtosis imaging of the liver at 3 tesla: in vivo comparison to standard diffusion-weighted imaging. Acta Radiol 2018;59:18-25.

198. Muthupillai R, Lomas DJ, Rossman PJ, et al. Magnetic resonance elastography by direct visualization of propagating acoustic strain waves. Science 1995;269:1854-1857.

199. Rouvière O, Yin M, Dresner MA, et al. MR elastography of the liver: preliminary results. Radiology 2006;240:440-448.

200. Sangwaiya MJ, Sherman DIN, Lomas DJ, et al. Latest developments in the imaging of fibrotic liver disease. Acta Radiol 2014;55:802-813.

201. $\mathrm{Xu} \mathrm{L}$, Lin Y, Han JC, et al. Magnetic resonance elastography of brain tumors: preliminary results. Acta Radiol 2007;48:327-330.

202. Li S, Chen M, Wang W, et al. A feasibility study of MR elastography in the diagnosis of prostate cancer at 3.0 T. Acta Radiol 2011;52:354-358.

203. Marticorena Garcia SR, Guo J, Dürr M, et al. Comparison of ultrasound shear wave elastography with magnetic resonance elastography and renal microvascular flow in the assessment of chronic renal allograft dysfunction. Acta Radiol 2018;59:1139-1145.

204. Axel L, Dougherty L: Heart wall motion. Improved method for spatial modulation of magnetization for MR imaging. Radiology 1989;I72:349-350.

205. Qi P, Thomsen C, Ståhlberg F, et al. Normal left ventricular wall motion measured with two-dimensional myocardial tagging. Acta Radiol 1993;34:450-456. 
206. Homsi R, Yuecel S, Schlesinger-Irsch U, et al. Epicardial fat, left ventricular strain, and T1-relaxation times in obese individuals with a normal ejection fraction. Acta Radiol 2019;60:1251-1257.

207. Thomsen $\mathrm{C}$, Jensen KE, Achten E, et al. In vivo magnetic resonance imaging and $31 \mathrm{P}$ spectroscopy of large human brain tumours at 1.5 tesla. Acta Radiol 1988;29:77-82.

208. Henriksen O, Larsson H, Jensen KM. In vivo 1H spectroscopy of the human brain at 1.5 tesla: preliminary experience at a clinical installation. Acta Radiol 1990;31:181186.

209. Sjøbakk TE, Lundgren S, Kristoffersen A, et al. Clinical $1 \mathrm{H}$ magnetic resonance spectroscopy of brain metastases at $1.5 \mathrm{~T}$ and $3 \mathrm{~T}$. Acta Radiol 2006;47:501-508.

210. Server A, Josefsen R, Kulle B, et al. Proton magnetic resonance spectroscopy in the distinction of high-grade cerebral gliomas from single metastatic brain tumors. Acta Radiol 2010;51:316-325.

211. Gao W, Wang X, Li F, et al. Cho/Cr ratio at MR spectroscopy as a biomarker for cellular proliferation activity and prognosis in glioma: correlation with the expression of minichromosome maintenance protein 2. Acta Radiol 2019;60:106-112.

212. Vassiou K, Tsougos I, Kousi E, et al. Application value of 3T 1H-magnetic resonance spectroscopy in diagnosing breast tumors. Acta Radiol 2013;54:380-388.

213. Thörmer G, Otto J, Horn L-C, et al. Non-invasive estimation of prostate cancer aggressiveness using diffusion-weighted MRI and 3D proton MR spectroscopy at 3.0 T. Acta Radiol 2015;56:121-128.

214. Chida K, Otani H, Saito H, et al. Feasibility of rapid-sequence 31P magnetic resonance spectroscopy in cardiac patients. Acta Radiol 2005;46:386-390.

215. Just N. Improving tumour heterogeneity MRI assessment with histograms. Br J Cancer $2014 ; 111: 2205-2213$. 
216. Lubner MG, Smith AD, Sandrasegaran K, et al. CT Texture analysis: definitions, applications, biologic correlates, and challenges. Radiographics 2017;37:1483-1503.

217. Ma X, Zhao X, Ouyang H, et al. Quantified ADC histogram analysis: a new method for differentiating mass-forming focal pancreatitis from pancreatic cancer. Acta Radiol 2014;55:785-792.

218. Woo S, Cho JY, Kim SY, et al. Histogram analysis of apparent diffusion coefficient map of diffusion-weighted MRI in endometrial cancer: a preliminary correlation study with histological grade. Acta Radiol 2014;55:1270-1277.

219. Cho SH, Kim GC, Jang Y-J, et al. Locally advanced rectal cancer: postchemoradiotherapy ADC histogram analysis for predicting a complete response. Acta Radiol 2015;56:1042-1050.

220. Erbay G, Onal C, Karadeli E, et al. Predicting tumor recurrence in patients with cervical carcinoma treated with definitive chemoradiotherapy: value of quantitative histogram analysis on diffusion-weighted MR images. Acta Radiol 2017;58:481-488.

221. Meng J, Zhu L, Zhu L, et al. Histogram analysis of apparent diffusion coefficient for monitoring early response in patients with advanced cervical cancers undergoing concurrent chemo-radiotherapy. Acta Radiol 2017;58:1400-1408.

222. Lee JY, Ahn KJ, Lee YS, et al. Differentiation of grade II and III oligodendrogliomas from grade II and III astrocytomas: a histogram analysis of perfusion parameters derived from dynamic contrast-enhanced (DCE) and dynamic susceptibility contrast (DSC) MRI. Acta Radiol 2018;59:723-731.

223. Ren J, Yuan Y, Shi Y, et al. Tumor heterogeneity in oral and oropharyngeal squamous cell carcinoma assessed by texture analysis of CT and conventional MRI: a potential marker of overall survival. Acta Radiol 2019;60:1273-1280. 
224. Gillies RJ, Kinahan PE, Hricak H. Radiomics: images are more than pictures, they are data. Radiology 2016;278:563-577.

\section{Figure legends}

Fig. 1. The total number of papers and MRI-related papers per year in Acta Radiologica for the period 1984-2019. Supplemental issues are not included.

Fig. 2. The number of MRI papers published in Acta Radiologica during the period 19842019 for the ten countries having published more than 50 papers. PRC: People's Republic of China. Korea: Republic of Korea (South Korea).

Fig. 3. The number of MRI papers published in Acta Radiologica during the three periods 1984-1999, 2000-2009, and 2010-2019 for the ten countries having published more than 50 papers during the whole period 1984-2019. PRC: People's Republic of China. Korea: Republic of Korea (South Korea).

Fig. 4. The number of MRI papers per radiological "subspecialty" published in Acta Radiologica during the period 1984-2019. Neu: neuroradiology, MS: musculoskeletal, Uro: urogenital, Abd: abdominal and gastrointestinal, Exp: experimental, Vas: vascular, HN: head \& neck, CM: contrast media, Car: cardiac, Misc: miscellaneous, MRS: MR spectroscopy, Ped: pediatric, Int: interventional radiology. 
250

200

150

100

50

0

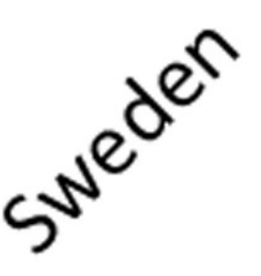

$\partial p^{\partial^{r}}$

$e^{e c} e^{e n r^{n t}}$

$200^{e^{2}}<n^{2 r^{r^{d}}}$

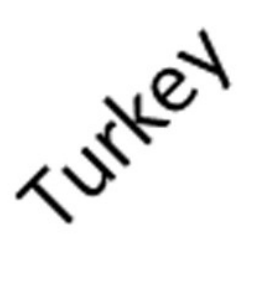

sp

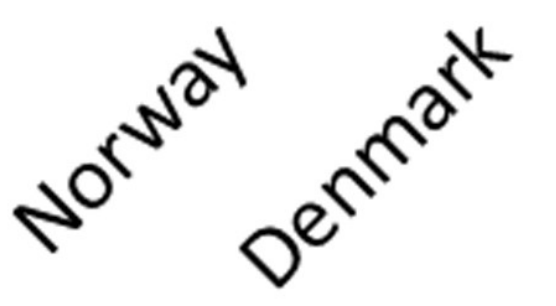




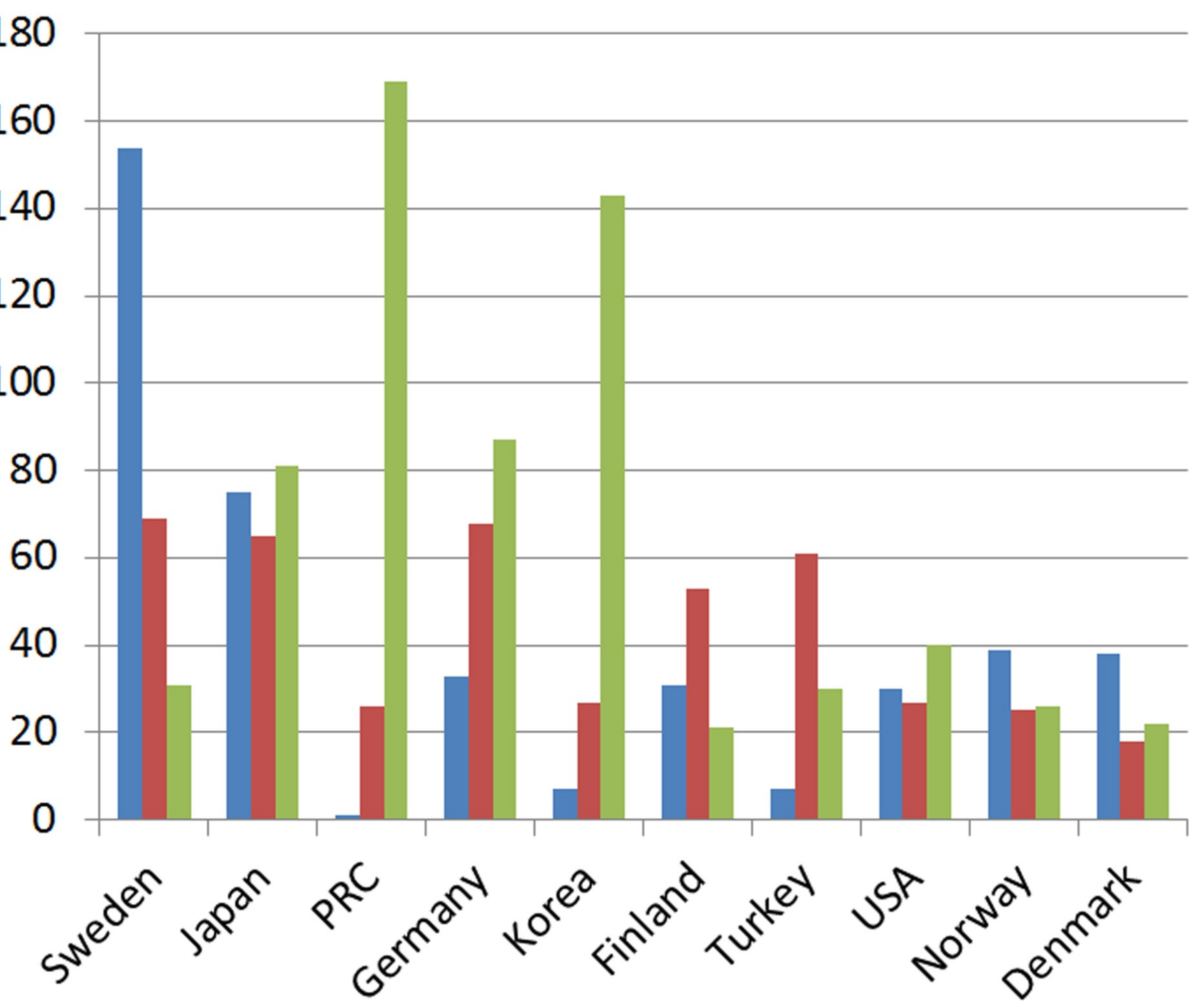

- 1984-1995

-2000-200s

2010-2019 


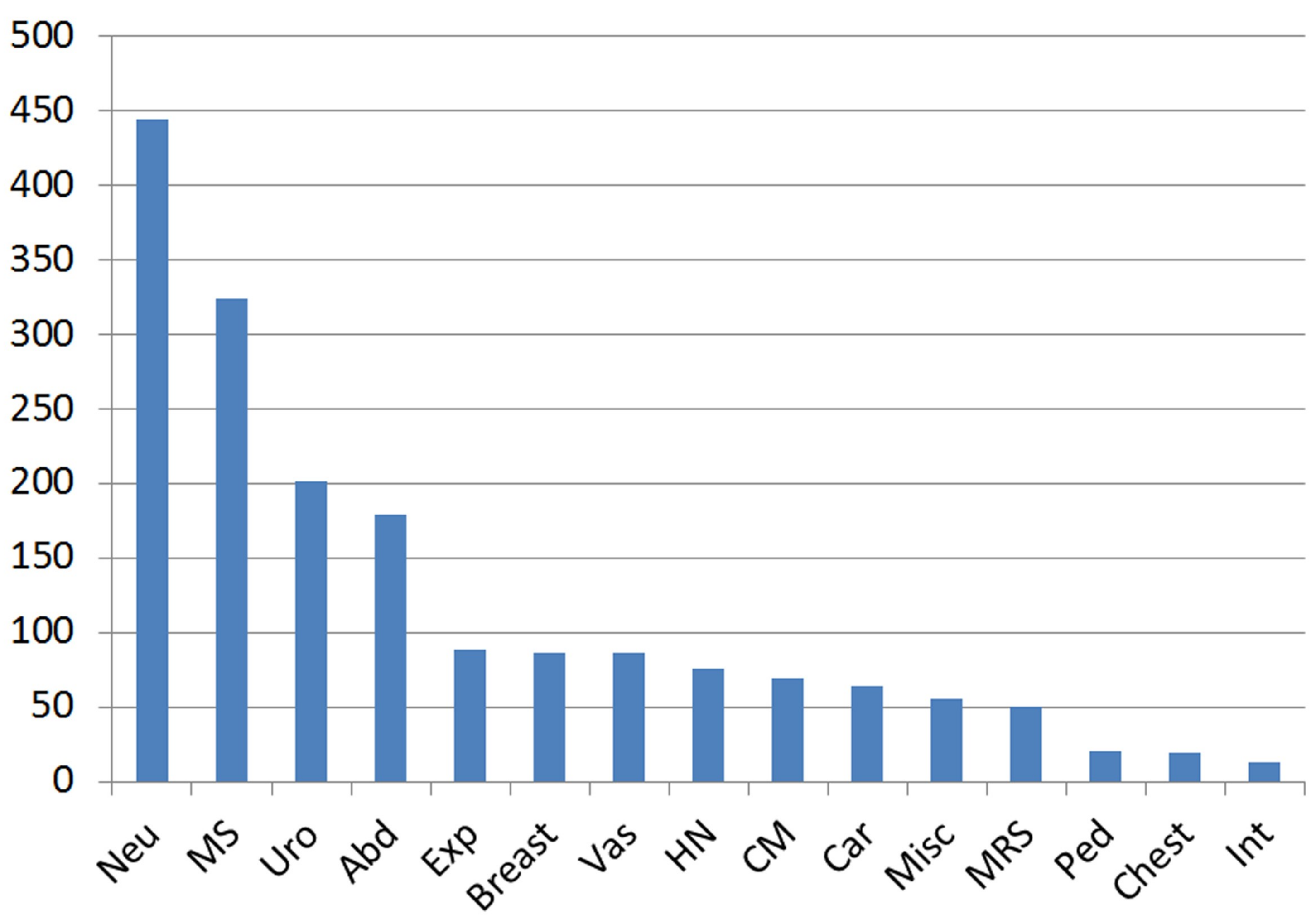

